\title{
Comercio, sobreexplotación laboral y ciclos en la periferia: una propuesta teórica y el caso ecuatoriano desde un modelo PVAR
}

\author{
CAJAS-GUIJARRO, JOHN \\ Universidad Central del Ecuador \\ Correo electrónico: jcajasg@uce.edu.ec \\ PÉREZ-ALMEIDA, BRYAN \\ Facultad Latinoamericana de Ciencias Sociales (Ecuador) \\ Correo electrónico: stev32_bry@hotmail.com
}

\begin{abstract}
RESUMEN
El presente artículo interpreta teóricamente cómo la competencia real capitalista internacional presiona a que en las sociedades periféricas los balances comerciales dependan de ventajas absolutas de costo basadas en una sobreexplotación laboralnatural, lo que crea dinámicas cíclicas en dichas sociedades. Para reforzar tal interpretación, el artículo toma como caso de estudio al capitalismo periférico ecuatoriano, sobre el que se presentan tendencias histórico-cíclicas de mediano y largo plazo, ejemplos de actividades económicas que al parecer sustentan sus superávits comerciales desde la sobreexplotación laboral-natural, y evidencia estadística de tendencias cíclicas de corto plazo a nivel sectorial, estimando un modelo PVAR sobre un panel de datos compuesto por 43 actividades económicas observadas en el período 2007-2016. Todos los resultados empíricos muestran la importancia de las ventajas absolutas de costo basadas en la sobreexplotación sobre los balances comerciales y el surgimiento de ciclos que refuerzan la condición dependiente del capitalismo ecuatoriano.
\end{abstract}

Palabras clave: competencia real, ventajas absolutas de costo, sobreexplotación, periferia capitalista, tendencias histórico-cíclicas, modelos PVAR.

Clasificación JEL: C33; F16; O11.

MSC2010: 62P20. 


\title{
Trade, super-exploitation of labor power and cycles in the periphery: a theoretical proposal and the Ecuadorian case through a PVAR model
}

\begin{abstract}
This paper theoretically interprets how international real capitalist competition pressures trade balances of the peripheral countries to depend on absolute cost advantages based on the super-exploitation of labor power and nature; dependence which creates cyclical dynamics within those countries. To reinforce such an interpretation, the paper takes as a study case the Ecuadorian peripheral capitalism, about which some historical-cyclical trends are presented as well as some examples of economic activities that seem to obtain their trade surplus through super-exploitation. Also, the paper estimates a PVAR model over a panel data of 43 economic activities observed during the period 2007-2016; from that estimation, it is found evidence of short-run cyclical dynamics among Ecuadorian economic activities. All the empirical results evidence the importance of the absolute cost advantages gained through super-exploitation of labor power and nature on the determination of trade balances and on the rise of cycles that reinforce the dependent condition of Ecuadorian capitalism.
\end{abstract}

Keywords: real competition, absolute cost advantages, super-exploitation, capitalist periphery, historical-cyclical trends, PVAR models.

JEL classification: C33; F16; O11.

MSC2010: 62P20.

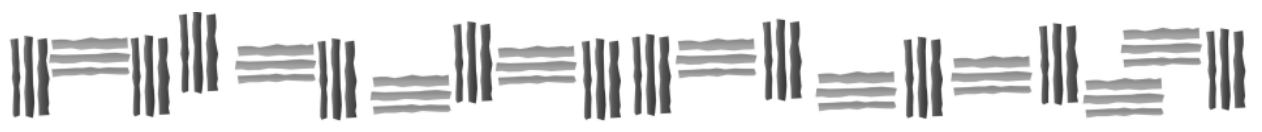




\section{Introducción.}

El sistema mundo capitalista posee una importante complejidad y heterogeneidad, que suele expresarse de diferentes formas al interior de las sociedades que lo conforman. En particular, la manera - muchas veces conflictiva - como realmente se da la competencia tanto entre capitales de un mismo sector como entre capitales de distinto sector (competencia real) a escala internacional puede provocar que los ciclos de la acumulación en las sociedades periféricas adquieran particularidades diferentes a los ciclos en países centrales. Por ejemplo, la competencia real vigente en el capitalismo internacional puede presionar a que varias actividades económicas de los países periféricos busquen sostener sus superávits comerciales por medio de la sobreexplotación tanto de la fuerza de trabajo como de la naturaleza. Sin embargo, esa dependencia en la sobreexplotación puede generar dinámicas cíclicas tanto a medio-largo plazo a nivel del conjunto de la economía de una sociedad capitalista periférica, como a nivel de actividades económicas. Semejantes dinámicas complican las posibilidades de alcanzar un pleno empleo en la periferia, e incluso podrían ampliar la vulnerabilidad de los ciclos periféricos ante shocks externos.

Considerando esta posibilidad, el presente artículo tiene como objetivo brindar una justificación teórica a la hipótesis de que la competencia real capitalista a escala internacional induce a que en la periferia los balances comerciales dependan de actividades económicas que obtienen ventajas absolutas de costo por medio de la sobreexplotación laboral y natural; dependencia que crea al interior de la periferia un peculiar comportamiento cíclico especialmente entre producción, subempleo, explotación laboral y balances comerciales (sección 2). Al revisar que la escasa literatura disponible sobre el estudio de la ventaja absoluta de costo no parece brindar evidencia que permita evaluar la hipótesis teórica planteada, el artículo plantea una alternativa metodológica basada en el uso de modelos de vectores autorregresivos aplicados a datos de panel (PVAR), desde los que se puede aplicar un test de causalidad de Granger, así como estimar funciones de impulso respuesta y de descomposición de varianza del error de predicción para evaluar la hipótesis de ciclicidad y de vigencia de una ventaja absoluta de costo basada en la sobreexplotación laboral-natural dentro de una sociedad capitalista periférica (sección 3). Posteriormente, se toma como caso de estudio al capitalismo periférico ecuatoriano (sección 4), sobre el que es posible identificar en términos referenciales algunas tendencias histórico-cíclicas de medio y largo plazo (subsección 4.1), identificar en términos descriptivos algunas actividades económicas ejemplares que al parecer sustentan sus superávits comerciales desde la sobreexplotación laboralnatural (subsección 4.2) y obtener evidencia estadísticamente significativa de tendencias cíclicas de corto plazo a nivel sectorial estimando un modelo PVAR sobre un panel de datos compuesto por 43 actividades económicas observadas en el período 2007-2016 (que comprende tanto el fin del segundo boom petrolero como el inicio de una nueva etapa de estancamiento) (subsección 4.3). Finalmente, el artículo concluye con un resumen de los principales resultados teóricos y empíricos obtenidos, y brinda algunas motivaciones para investigaciones futuras (sección 5).

\section{Motivación teórica: competencia real, ventaja absoluta y efectos en la periferia.}

En esta sección se discuten teóricamente los potenciales efectos de la competencia real y la vigencia de la ventaja absoluta de costo en el comercio internacional sobre la periferia capitalista. Para ello se combinan las reflexiones sobre la competencia real de Shaikh (2016) con algunos planteamientos del estructuralismo y la dependencia sobre las diferencias estructurales entre centros y periferia capitalista. Como resultado se justifica un posible vínculo cíclico entre producción, subempleo, explotación laboral y balances comerciales en sociedades capitalistas periféricas donde las ventajas absolutas de costo de los diferentes sectores no se enfocan en la productividad sino en la sobreexplotación laboral-natural. 


\subsection{Competencia real intra e intersectorial y capitales reguladores.}

En el capitalismo, cada empresa busca ganancias y, sobre todo, acumular capital (“iAcumulad, acumulad! ¡He ahí a Moisés y los profetas!” (Marx [1867] 2009:735)). Durante la búsqueda de esos objetivos las empresas capitalistas colisionan en una competencia real que implica una dinámica principalmente, aunque no solo, de conflicto entre capitalistas, donde tanto precios como tasas de ganancia fluctúan permanentemente alrededor de varios centros de gravitación móviles, surgiendo procesos de "equilibrio turbulento" (característica que distingue a la competencia real de la competencia perfecta neoclásica) (Shaikh, 2016: 259-260).

Dicha competencia real capitalista se desenvuelve a nivel intra e intersectorial. En la competencia real intrasectorial las empresas pertenecen a un mismo sector que produce mercancías idénticas y donde la fijación del precio se usa como principal instrumento tanto para atraer compradores como para dañar a los competidores dentro del sector. Como en un contexto de mercancías idénticas los compradores escogen los precios más bajos, las empresas están presionadas a recortar costos, proceso que induce a cierta convergencia de precios entre competidores; tendencia recogida en la "ley de los precios correlacionados" (Shaikh, 1980b), que se distingue de la "ley del precio único" neoclásica en tanto que esta última indicaría que la igualación de precios se debe a que las empresas poseen características similares y no surge como resultado de la presión causada por la competencia capitalista real (ver Tsaliki, Paraskevopoulou \& Tsoulfidis 2018: 1045). Otra diferencia relevante entre la competencia perfecta neoclásica y la competencia capitalista real es que para la primera las ganancias extraordinarias nacen de un fallo en los procesos de competencia, en cambio dichas ganancias son una característica innata para la segunda perspectiva (como se verá más adelante).

Mientras que la competencia real tiende a igualar los precios dentro de cada sector, en cambio las condiciones técnicas de producción suelen distribuirse de forma desigual en especial por la heterogeneidad entre empresas causada por procesos como la movilidad o la concentración y centralización del capital. Esa heterogeneidad genera diferentes estructuras de costos entre empresas de un mismo sector que, al combinarse con la igualación sectorial de precios, llevan a una tendencia a la desigualdad de tasas de ganancia entre empresas de un mismo sector (Shaikh, 2016: 262).

Si bien la competencia intrasectorial describe la heterogeneidad de tasas de ganancia al interior de los sectores (este resultado es similar a la propuesta de Botwinick $(1993,2017)$ sobre el surgimiento de diferenciales en las tasas de ganancia durante la competencia capitalista), no explica la relación entre las tasas de ganancia de distintos sectores. Es aquí donde influye la competencia real intersectorial, donde los capitales se movilizan de aquellos sectores que, en general, ofrecen una tasa de ganancia relativamente baja a aquellos que ofrecen una tasa relativamente alta. Esa movilización de capitales tiende a nivelar las tasas de ganancia y a crear precios de producción alrededor de los que fluctúan los precios de mercado de los distintos sectores (Marx [1894] 2009: 195-217; Boundi, 2019:124; Tsaliki, Paraskevopoulou \& Tsoulfidis, 2018:1045; Shaikh 2016: 265).

Así, entre la competencia intra e intersectorial surgen tendencias en apariencia opuestas, la una de divergencia y la otra de nivelación de las tasas de ganancia. Tal oposición se resuelve, según Shaikh (1990, 2016), con la existencia de capitales reguladores: conjuntos de capitales que poseen las condiciones productivas de mejor reproducción dentro de un sector (Shaikh, 2016:265; Botwinick, 1993:152-53; Tsoulfidis \& Tsaliki, 2005:13). Según las características concretas de cada sector, los capitales reguladores tendrán sus propias condiciones de producción; sin embargo, en general, dichos capitales suelen caracterizarse por poseer los costos unitarios sectorialmente más bajos (Shaikh, 2016:265-67).

Dada su condición de mejor reproducibilidad, la tasa de ganancia de los capitales reguladores se vuelve la principal motivación para la movilidad de capitales. Es decir, cuando la tasa de ganancia de los capitales reguladores de un determinado sector es mayor (menor) que la tasa de los capitales reguladores de otros sectores, los nuevos capitales ingresan a (salen de) ese sector. Si bien los capitales reguladores motivan al movimiento de capitales en búsqueda de una mayor tasa de ganancia, las 
condiciones concretas de las nuevas inversiones no siempre coinciden con las que, a priori, poseen los costos más bajos. De hecho, la movilización del capital puede generar nuevas inversiones hacia empresas con: condiciones y costos promedio (p.ej. cuando hay un solo método de producción o métodos muy similares); costos más altos (p.ej. cuando existen rendimientos decrecientes, como en la agricultura); costos más bajos (p.ej. cuando los métodos más costosos son los más antiguos y dejan de ser competitivos, o cuando existen rendimientos crecientes) (Shaikh, 2016:265-67). La vigencia de uno $\mathrm{u}$ otro caso depende de las condiciones concretas de cada sector.

Es por ello que sobre los capitales reguladores se acentúan los ciclos de la acumulación de capital (sobre la interpretación cíclica de la acumulación y su vínculo con las crisis recurrentes del capitalismo se recomienda el trabajo de Laibman (1992, parte III) así como el trabajo de Cajas-Guijarro (2018)), a la vez que estos capitales actúan como "precio-determinantes de cada sector merced a que sus condiciones técnicas de producción son las mejor reproducibles" (Boundi, 2019:124). Así, en cada sector los capitales reguladores son líderes en la definición de precios, mientras que los capitales noreguladores actúan como seguidores de los precios definidos por los capitales reguladores (Shaikh, 2016:268).

Resultado de la interacción entre la competencia intra e intersectorial, las tasas de ganancia de los capitales reguladores de diferentes sectores tienden a igualarse sin que eso implique la igualdad en las tasas promedio de ganancia de los sectores (de igual manera la competencia real tampoco iguala las tasas promedio de ganancia entre países) (Shaikh, 2016:269). La única forma para que la competencia real iguale las tasas medias de ganancia sectoriales es que todas las empresas dentro de un sector sean idénticas (es decir, igualdad entre cualquier empresa capitalista individual, las empresas de capital promedio y las empresas de capital regulador). Semejante supuesto restrictivo es justo lo que la economía ortodoxa asume de forma explícita mientras que la economía heterodoxa lo suele asumir implícitamente según Shaikh (2008:167-71, 2016:269-70). Es decir, al interior de cada sector las empresas poseen tasas de ganancia distintas, mientras que entre sectores hay una tendencia a la igualdad en las tasas de ganancia, pero solo de las empresas de capitales reguladores. A su vez, esos capitales reguladores definen los precios al interior de su respectivo sector, mientras que los demás capitales actúan como seguidores (para un resumen más detallado de algunas características de la competencia real capitalista intra e intersectorial, ver Shaikh (2016:271)). Esta dinámica de la competencia capitalista real tiene efectos relevantes sobre el comercio internacional como, por ejemplo, la vigencia de las ventajas absolutas de costo.

\subsection{Ventaja absoluta de costo y ganancias extraordinarias.}

A nivel internacional, la competencia real capitalista se da entre empresas tanto de un mismo país como de diferentes países (Shaikh, 2016:496-97; Emmanuel, 1972:240). Mientras que al interior de un país, sobre todo la competencia intrasectorial lleva a que las empresas recorten sus costos para reducir sus precios y desplazar a la competencia, en el comercio internacional dicha competencia intrasectorial provoca la vigencia del principio de costo absoluto (Smith [1776] 1973): los capitales ubicados en naciones de producción más eficiente o de salarios más bajos son probablemente más exitosos en la arena internacional, pues tales características permiten reducir costos de manera absoluta, es decir, otorgan una ventaja absoluta de costo (Shaikh 2016:502, 1980a, 1980b).

En otras palabras, cuando la competencia real capitalista se vuelve internacional, las empresas que producen una mercancía deben enfrentarse a los productores de la misma mercancía en su propio país y en otros países. Tal competencia intrasectorial hace que los costos unitarios sean cruciales pues el más bajo de éstos define a los capitales reguladores (Shaikh, 2016:510) los que, a su vez, determinan los precios de producción a escala global (Tsaliki et al., 2018:1045). Como resultado, a diferencia de la perspectiva convencional de las ventajas comparativas (Ricardo [1817] 1951), la noción de la ventaja absoluta de costo considera que los capitales de costos más bajos determinan el comercio internacional y aquellos países con capitales más costosos (y menos competitivos) sufren de crónicos déficits comerciales que son cubiertos con endeudamiento externo, aun bajo condiciones de "libre mercado" (Shaikh, 2016:505). Shaikh (2016:508-509) sugiere en especial dos críticas al enfoque ricardiano de las 
ventajas comparativas aplicadas al comercio internacional: (a) al analizar el ajuste de precios necesario para alcanzar el equilibrio comercial Ricardo no toma en cuenta que precios y costos de producción se retroalimentan; (b) el enfoque ricardiano no considera adecuadamente las dinámicas de la balanza de pagos, en tanto que el desequilibrio comercial coexiste con el movimiento de capitales y/o la variación del endeudamiento. Para una comparación teórica entre el enfoque de la ventaja absoluta de Smith y las ventajas comparativas de Ricardo en el comercio internacional, ver Tsoulfidis y Tsaliki (2019, cap.7).

A criterio de Shaikh (2016:522), la vigencia de la ventaja absoluta de costo en el comercio internacional posee las siguientes implicaciones: (a) los costos comparativos y los términos de intercambio entre sectores se determinan por salarios reales relativos y productividades relativas de los capitales reguladores; (b) la dirección del balance comercial es determinada por la ventaja o desventaja absoluta de costo (mecanismo clásico) mientras que su magnitud depende de los ingresos nacionales relativos (mecanismo keynesiano); (c) los desbalances comerciales crean desbalances en las demás cuentas de la balanza de pagos, generando efectos sobre las tasas de interés que inducen a movimientos internacionales de capital en el corto plazo (mecanismo clásico) y afectan al ingreso nacional y a la producción por su efecto sobre la inversión (mecanismo keynesiano). Como corolario, los países con ventaja absoluta de costo obtienen superávits comerciales que los reciclan como préstamos al resto del mundo, mientras que los países con desventaja absoluta de costo adquieren déficits comerciales que los cubren con endeudamiento.

Además de los efectos mencionados, la vigencia de la ventaja absoluta de costo en el comercio internacional es relevante para describir cómo las ganancias extraordinarias surgen y se distribuyen de forma heterogénea entre empresas de países diferentes. A criterio de Boundi (2019), pueden distinguirse dos procesos que explican dichas ganancias en el contexto del comercio internacional: intercambio desigual y trabajo potenciado.

Intercambio desigual. Desde esta perspectiva, las ganancias extraordinarias provienen de la transferencia de valor desde las empresas tecnológicamente más rezagadas (y, por tanto, más intensivas en el uso de fuerza de trabajo y con menor composición orgánica del capital) a aquellas tecnológicamente más aventajadas (y de mayor composición orgánica). Tal visión coincide con la noción del intercambio desigual entre empresas capitalistas, que se desenvuelve en la esfera de la circulación (Grossman [1929] 2004; Carchedi, 1991; Shaikh, 1990, 2016; Boundi, 2019:121-23; Emmanuel, 1972). En términos muy generales, dentro de esta interpretación se puede aproximar a la composición orgánica del capital - en precios - a través de la ratio entre el dinero gastado en medios de producción (proxy del capital constante marxista) y el dinero gastado en fuerza de trabajo (proxy del capital variable marxista).

Trabajo potenciado. Según esta perspectiva, las ganancias extraordinarias se obtienen por las empresas de mejores condiciones técnicas de producción pues en éstas existe un trabajo potenciado (se produce la misma mercancía con un tiempo de trabajo menor al socialmente necesario) capaz de crear mayor valor en un mismo lapso de tiempo (aquí la ganancia extraordinaria desaparece cuando se estandariza la técnica de producción más eficiente). Esta visión, que coincide con la noción de plusvalor extraordinario generado desde la producción (Marx [1867] 2009:379-90; Boundi, 2019:123), sugiere que "los sectores exportadores de las naciones que disfrutan de saldos comerciales superavitarios generan más valor por unidad de tiempo" (Boundi, 2019:127; Astarita, 2013).

Aunque Boundi presenta ambos enfoques como "contrapuestos" (2019:123), quizá sea más acertado pensar que, en un contexto de "desarrollo capitalista desigual", cada proceso (intercambio desigual y trabajo potenciado) cumple diferentes roles para los capitales reguladores de las múltiples regiones que componen un heterogéneo sistema-mundo capitalista que, por simplicidad, se va a dividir entre centros y periferia (Wallerstein, 2005). La distinción centro-periferia que se emplea a continuación no niega la existencia de estructuras que podrían catalogarse como "sub-centros" o "subperiferias" (Marini, 1973; Wallerstein, 2005; Osorio, 2015; Sotelo, 2017), que se dejan para una discusión teórica futura. 
También se podría reflexionar sobre el surgimiento de ganancias extraordinarias a través de otros procesos asociados, por ejemplo, a la acumulación por desposesión propuesta por Harvey (2003).

\subsection{Interacción centro-periferia en un contexto de competencia real capitalista.}

Para comprender los potenciales efectos de la competencia real y la formación de ganancias en un sistema mundo capitalista compuesto por estructuras centro-periféricas, se puede proceder en dos pasos: primero se considera lo que sucede al interior de cada región de forma aislada y asumiendo solo competencia intrasectorial; luego se analiza la situación cuando ambas regiones (centros-periferia) interactúan y rige tanto la competencia real intra como intersectorial. Esta reflexión podría complejizarse considerando la existencia de cadenas globales de valor en donde la periferia se especializa en productos de bajo valor agregado que sirven de insumos para la producción de mercancías sofisticadas en los centros, todo en un proceso global de producción de plusvalor (Kaplinsky \& Morris, 2000; Gereffi, 2001; Carballa, Cédric \& Knauss, 2016; Grinberg, 2016; Johnson, 2018).

\subsubsection{Competencia intrasectorial con centros y periferia aislados}

Si se considera aisladamente a los centros y la periferia y se asume solo competencia real intrasectorial, es posible distinguir algunas tendencias. Por un lado, si se acepta la intuición estructuralista de que el progreso técnico no se difunde plenamente a través del comercio internacional, sino que se concentra mayormente en los centros (Prebisch, 1950, 1984:13-15), entonces al interior de esos centros los capitales reguladores obtienen sus ventajas absolutas de costo aplicando condiciones de producción técnicamente avanzadas que abaratan tanto el uso de fuerza de trabajo como el uso de insumos. Además, el uso de condiciones de producción mejores al promedio hace que, al interior de los centros y a un nivel de competencia real intrasectorial, los capitales reguladores obtengan ganancias extraordinarias gracias a la aplicación de trabajo potenciado. Nótese que tales ganancias nacen de la producción y surgen incluso si en los centros no existiera competencia real intersectorial ni relaciones con la periferia.

Igualmente desde una intuición estructuralista puede sugerirse que, por la escasa difusión del progreso técnico hacia la periferia, en el interior de ésta rige una heterogeneidad estructural en donde coexisten muy pocos sectores modernos de condiciones técnicas avanzadas, alta productividad y altos salarios y múltiples sectores tradicionales de condiciones técnicas rezagadas, baja productividad y bajos salarios (Pinto, 1969). Esa heterogeneidad hace que, al interior de la periferia y a un nivel de competencia real intrasectorial, emerjan dos patrones: los capitales reguladores modernos obtendrían ventajas absolutas de costo con condiciones técnicas de producción avanzadas que permiten aplicar trabajo potenciado y obtener ganancias extraordinarias (situación similar a los centros). En cambio, desde una intuición dependentista podría plantearse que los capitales reguladores tradicionales, al poseer condiciones técnicas rezagadas, obtienen sus ventajas absolutas pagando a la fuerza de trabajo un salario menor y/o exigiendo una intensidad laboral mayor al promedio sectorial, es decir, aplican una sobreexplotación laboral que amplía las ganancias al crear plusvalor relativo, lo que incrementa la tasa de explotación y genera un elevado subempleo (entendido de forma muy genérica como el empleo de fuerza de trabajo bajo condiciones de sobreexplotación laboral) (Marini, 1973; Cajas-Guijarro, 2015; Marx [1867] 2009). "La ventaja absoluta no es sino ventaja en la tasa de explotación o tasa de plusvalía" (Guerrero, 1995). Aquí va a entenderse que la tasa de explotación puede aproximarse de forma muy general por medio de la relación entre ganancias capitalistas y el gasto total en salarios (como proxy a la relación plusvalor/capital variable marxista).

Asimismo, ante el retraso de sus condiciones técnicas de producción, los capitales reguladores tradicionales también pueden buscar ventajas absolutas de costo a través de la sobreexplotación de la naturaleza por medio de la expansión de actividades extractivistas. Por extractivismo puede entenderse a la extracción masiva de recursos naturales, casi sin procesar, con el único propósito de exportarlos a los mercados internacionales (ver Gudynas, 2009). Cabría pensar en un potencial vínculo entre extractivismo y especulación financiera, tema que se propone para una investigación futura. En todos los casos, nótese que las ganancias en los sectores modernos y tradicionales nacen en la producción y 
la distribución y existen incluso si la periferia no tuviera competencia real intersectorial ni ninguna relación con los centros.

\subsubsection{Competencia intra e intersectorial con interacción centros-periferia}

Ahora se considera el caso de centros y periferia interactuando bajo competencia real intra $e$ intersectorial. Por un lado, la concentración del progreso técnico en los centros hace que sus capitales reguladores locales sean también reguladores a nivel global en los sectores donde las ventajas absolutas de costo por mejores condiciones técnicas superan a las ventajas absolutas de la periferia. En cambio, en los sectores donde las ventajas absolutas provenientes de la sobreexplotación laboral-natural en la periferia se sobreponen a aquellas ventajas de los centros, sucederá que los capitales reguladores periféricos de sectores tradicionales serán también reguladores a escala global (en teoría podría pensarse en casos donde las condiciones técnicas de los sectores modernos de la periferia superen a los centros $\mathrm{y}$, por tanto, los capitales reguladores modernos de la periferia se vuelvan reguladores también a nivel global. Por ahora este caso se deja de lado pues parece más bien excepcional bajo las condiciones actuales de la competencia capitalista internacional). Así, las diferencias estructurales entre centros y periferia llevan a que la competencia intersectorial se dé preferentemente a través del movimiento internacional de capitales entre capitales reguladores centrales altamente tecnificados (cuya ventaja absoluta de costo global se basa en condiciones técnicas de producción avanzadas) y capitales reguladores periféricos tradicionales (que sustentan su ventaja absoluta global en la sobreexplotación laboral-natural). Tales capitales reguladores definirían los precios de producción de los sectores involucrados en el comercio internacional, mientras que los capitales no-reguladores tanto del centro como de la periferia actuarían como seguidores. Esta interpretación es relativamente cercana a la intuición sobre la competencia capitalista y la formación de "precios monopólicos" entre centros y periferia sugerida por Dussel (2008).

A su vez, recordando que los centros capitalistas concentran el progreso técnico, podría considerarse que los capitales reguladores centrales altamente tecnificados poseen elevadas composiciones orgánicas de capital mientras que los capitales reguladores periféricos tradicionales poseen composiciones orgánicas bajas. Dicha diferencia entre composiciones orgánicas hace que los movimientos de capital causados por la competencia intersectorial, que tienden a nivelar las tasas de ganancia de los capitales reguladores a escala global, generen un intercambio desigual en donde parte de las ganancias de los capitales reguladores periféricos se transfieran a los capitales reguladores centrales (Emmanuel, 1972; Amin, 1974; Amín et al., 1976; Marx [1894] 2009). De ese modo, las ganancias extraordinarias de los capitales reguladores centrales altamente tecnificados se obtendrían tanto del trabajo potenciado (que aventaja a estos capitales en comparación a los capitales seguidores centrales y periféricos) como del intercambio desigual que mantienen con los capitales reguladores periféricos tradicionales, tal como se ilustra en el Gráfico 1.

En resumen, la competencia real crea capitales reguladores centrales altamente tecnificados que generan balances comerciales positivos para los centros capitalistas tanto por las ganancias extraordinarias recibidas por trabajo potenciado como por intercambio desigual. En cambio, esa misma competencia real crea capitales reguladores periféricos tradicionales que buscarían balances comerciales positivos para la periferia con una ventaja absoluta de costo basada en la sobreexplotación laboral-natural, que en el caso laboral incrementa el subempleo y la tasa de explotación mientras que en el caso natural expande las actividades extractivistas que sobreexplotan a la naturaleza. Por tanto, en la periferia se podría considerar que el balance comercial de cada sector estaría muy vinculado a la ventaja absoluta de costo generada por la sobreexplotación laboral, el alto subempleo, una elevada tasa de explotación y la participación de actividades basadas en el extractivismo. Y cuando la sobreexplotación laboral-natural no genera una ventaja absoluta suficiente, surge un déficit comercial en la periferia que afecta negativamente su ingreso, su producción y le presiona a incrementar su endeudamiento externo. 


\section{Gráfico 1. Competencia real entre capitales del centro y la periferia.}

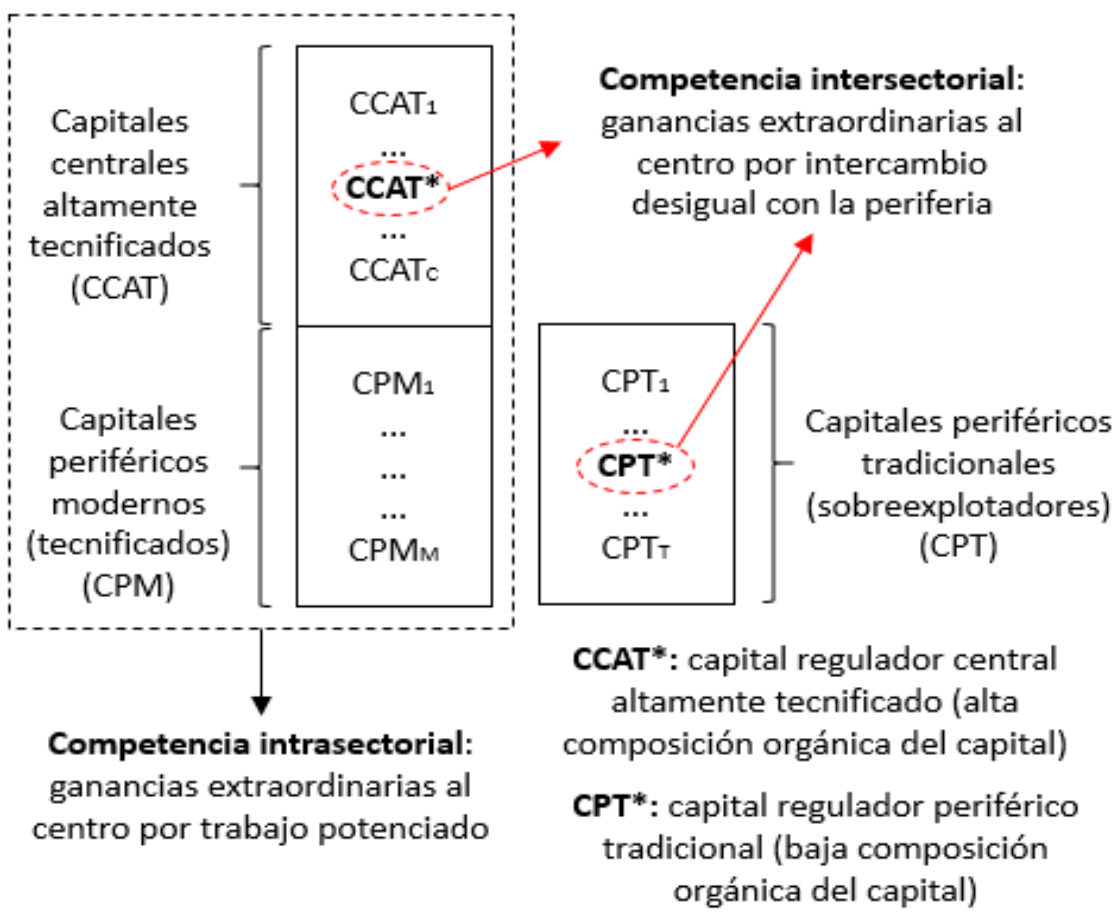

Fuente: Elaboración propia.

Además, este efecto de la competencia real a escala internacional permite sugerir un potencial vínculo cíclico dentro de la periferia entre producción-ingreso, subempleo, explotación laboral y balance comercial. Una dinámica que hace recordar la causación circular acumulativa sugerida por Myrdal (1957). Por ejemplo, un incremento exógeno del producto causado por una expansión autónoma de la demanda agregada puede reducir el subempleo e incrementar el poder de negociación de los trabajadores para exigir mejores salarios y condiciones laborales, lo que reduce la explotación laboral y, por tanto, también reduce la tasa de explotación (Goodwin, 1967; Cajas-Guijarro, 2018). Como los capitales reguladores periféricos tradicionales basan una parte de sus ventajas absolutas de costo en la sobreexplotación laboral, entonces una menor tasa de explotación reduce dichas ventajas absolutas y, por tanto, se tiende al déficit comercial y a una potencial contracción del ingreso y la producción. Sin embargo, esa contracción de la producción-ingreso puede deteriorar las condiciones laborales, aumentar el subempleo, debilitar a los trabajadores, aumentar la tasa de explotación y recuperar la ventaja absoluta de costo sobreexplotadora que tiende a generar un superávit comercial, lo que aumenta la produccióningreso y consolida el proceso cíclico. Así, bajo esta interpretación, en la periferia surge una causalidad que podría ir de la producción-ingreso al subempleo, luego a la tasa de explotación, a los balances comerciales (por la ventaja absoluta de costo basada en la sobreexplotación) y, de nuevo a la producción-ingreso. Esta interpretación podría hacerse en términos más formales usando como referencia la síntesis propuesta por Dávila-Fernández et al. (2019) en donde se junta el efecto del poder de negociación de los trabajadores en los salarios, la endogeneidad del progreso técnico y las restricciones al crecimiento económico por balanza de pagos en un proceso cíclico. A dicha síntesis se podría agregar el vínculo entre el balance comercial periférico y la sobreexplotación laboral proveniente de la vigencia del principio de la ventaja absoluta de costo, así como los movimientos de capitales causados por la competencia real. Dicha interpretación analítica se deja planteada para un trabajo futuro.

En conclusión, la competencia real internacional hace que en la periferia los capitales reguladores tradicionales busquen ventajas absolutas de costo y superávits comerciales con la sobreexplotación laboral-natural. Por cierto, dicha sobreexplotación suele ubicarse en sectores exportadores sobre todo 
de productos primarios carentes de tecnificación, lo que entrampa a la periferia en una situación que impide transformaciones estructurales que incrementen la productividad de sus procesos de producción y mejoren las condiciones de empleo. Para algunos, la posibilidad de que en la periferia se pueda sobreexplotar a la fuerza de trabajo y a la naturaleza con mayor facilidad que en los centros crea incluso una suerte de maldición de la abundancia en donde esa sobreexplotación laboral-natural junto con el "rentismo" y otras "patologías" refuerzan las estructuras periféricas. Para una discusión al respecto ver Acosta y Cajas-Guijarro (2016a, 2016b).

Además, al no darse dichas transformaciones, se refuerza el poder de los capitales reguladores centrales altamente tecnificados, mientras que la periferia termina en una condición de dependencia (Dos Santos, 1970): para mantener sus procesos de acumulación, la periferia requiere importar los medios de producción creados por los centros, cargados de sofisticación técnica y vendidos a precios impuestos por los capitales reguladores centrales. Para financiar esas importaciones, la periferia incurre en superávits comerciales sostenidos desde las ventajas absolutas ganadas por la sobreexplotación laboral-natural, y cuando esos superávits son insuficientes o decaen, no queda más alternativa que recurrir al endeudamiento externo (que, por cierto, también tendría un potencial comportamiento cíclico). Basta revisar la situación contemporánea concreta de las sociedades periféricas para comprender que esta interpretación de cómo se insertan en el sistema mundo capitalista parece más plausible que la interpretación convencional propuesta desde el principio de las ventajas comparativas y sus distintas variantes contemporáneas.

\section{Breve revisión de literatura empírica y propuesta metodológica.}

Los intentos de evaluar empíricamente los efectos de la vigencia de las ventajas absolutas de costo en un contexto de competencia real internacional son escasos (mucho más abundantes son, por ejemplo, los intentos de estudiar empíricamente el intercambio desigual. Sobre el debate teórico del intercambio desigual y los intentos por operacionalizarlo empíricamente se recomienda ver la reseña de Ricci (2019:227-28)). Entre esos intentos se encuentra el trabajo de Seretis y Tsaliki (2016) quienes, usando información insumo-producto, estiman que la existencia de ventajas absolutas de costo entre cuatro países de la zona euro (Grecia, España, Finlandia y Holanda) lleva al surgimiento de transferencias de valor propias del intercambio desigual. A su vez, Tsaliki et al (2018), también usando información insumo-producto, estiman que Alemania tendría una ventaja absoluta de costo en su comercio con Grecia, lo que provocaría un intercambio desigual reflejado en la transferencia de valor desde Grecia a Alemania. Por su parte, Tsoulfidis y Tsaliki (2019, cap.7), igualmente usando información insumoproducto y datos de comercio bilateral, muestran la aplicabilidad del principio del intercambio desigual y la vigencia de las ventajas absolutas de costo en el comercio bilateral de tres pares de países, Alemania-Grecia, Estados Unidos-China y Estados Unidos-Alemania, encontrando que las transferencias de valor de los países menos avanzados a los más avanzados estaría más vinculadas a los movimientos de capitales y las productividades entre países, y menos vinculadas a la contracción salarial.

Otro grupo de trabajos relevantes incluye a Boundi (2017), donde por medio de un test de cointegración se estima que el tipo de cambio real efectivo entre España y Alemania depende a largo plazo de los costos laborales relativos unitarios de las industrias de cada país (como resultado de la vigencia de la ventaja absoluta de costo). De forma similar, Boundi (2019) usa información de The World Input-Output Database Release 2016 y un análisis de cointegración en panel para mostrar que el tipo de cambio real efectivo entre sectores manufactureros españoles y de los demás socios de la Unión Europea se encuentra regulado por los costos laborales y por las diferencias intrasectoriales de la tasa de ganancia.

A diferencia de estos y otros trabajos, el presente artículo no busca estudiar la vigencia de la ventaja absoluta de costo en el comercio bilateral entre países capitalistas relativamente desarrollados o algún vínculo histórico entre costos laborales y tipo de cambio real. Más bien busca estudiar la 
potencial dinámica cíclica entre producción-ingreso, subempleo, explotación laboral y balances comerciales al interior de los países de la periferia capitalista a causa de la relación comercial que mantienen sus actividades económicas con el resto del mundo; relación en teoría regida por la competencia real capitalista y por la búsqueda de ventajas absolutas de costo basadas en la sobreexplotación laboral-natural, tal como se sugirió en la motivación teórica de la sección 2.

Para evaluar la existencia de la retroalimentación cíclica sugerida en términos teóricos dentro de las diferentes actividades económicas al interior de un país capitalista periférico, se propone usar un modelo de vectores autorregresivos en datos de panel (PVAR) donde se usa un panel de datos cuya dimensión temporal recoge cada instante de tiempo $t$ (p.ej. años), mientras que su dimensión transversal recoge a cada actividad económica $c$ del país periférico que mantiene relaciones comerciales con el resto del mundo. Dentro de dichas actividades cabría incluir tanto a aquellas intensivas en fuerza de trabajo como aquellas basadas en el extractivismo a fin de incluir el efecto sobre los demás sectores generados por el ingreso de recursos a causa de las exportaciones de productos primarios casi sin procesar.

Dadas las dimensiones temporal y transversal, y siguiendo la propuesta de Canova y Ciccarelli (2004) y Love y Zicchino (2006), se puede construir un modelo PVAR con una especificación como la que se presenta en la expresión (1).

$$
Y_{c t}=A_{t} Y_{c t-1}+\cdots+A_{i} Y_{c t-1}+\cdots+A_{p} Y_{c t-p}+V_{c t}
$$

donde $Y_{c t}=\left(Y_{c t}^{1}, \ldots, Y_{c t}^{k}\right)^{T}$ es un vector que contiene a las $k=4$ variables de interés sobre las cuales se asume un comportamiento endógeno y cíclico para las actividades económicas del país periférico dentro del período de tiempo estudiado (producto, tasa de subempleo, tasa de explotación y balances comerciales), $A_{i}$ es una matriz de parámetros asociada al i-ésimo rezago del vector de variables $Y_{c t-i}, V_{c t}=\left(v_{c t}^{1}, \ldots, v_{c t}^{k}\right)^{T}$ es un vector de efectos no recogidos por los componentes autorregresivos, y $p$ es el número total de rezagos a emplear en el modelo.

Debido a las diferencias idiosincráticas que poseen las múltiples actividades económicas al interior de un país periférico (las cuales complican la estimación de un comportamiento empírico general), es adecuado que en la modelación PVAR se controlen los efectos fijos del panel de datos. Para aplicar dicho control se usa la transformación de Helmert (Lee \& Yu, 2010), lo que también mitiga los problemas de correlación que podrían emerger en los retardos de las variables endógenas (Love \& Zicchino, 2006).

A su vez, para que la aplicación de un modelo PVAR no genere resultados espurios ni un comportamiento explosivo ante shocks exógenos, se debe verificar que las variables utilizadas en el modelo sean estacionarias o en su defecto que dichas variables hayan recibido las transformaciones adecuadas hasta alcanzar la estacionariedad (Lardic \& Mignon, 2002; Melguizo, 2015). Para esta verificación de estacionariedad se puede aplicar tanto el test de estacionariedad individual de LevinLin-Chu (Levin, Lin \& Chu, 2002) como el test de estacionariedad conjunta de los multiplicadores de Lagrange de Hadri (2000). Asimismo, para evaluar que las variables endógenas no generan comportamientos explosivos dentro del modelo PVAR, se puede obtener los valores propios $\lambda^{i}$ del determinante $\left|\lambda^{p} I-\lambda^{p-1} A_{1}-\cdots-A_{p}\right|=0$ y revisar que todos se encuentran dentro del círculo unitario (Hamilton, 1994).

Para estimar los parámetros y los efectos no recogidos por las variables endógenas del modelo PVAR (es decir, estimar $A_{i}$ y $V_{c t}$ ) se puede usar el método generalizado de momentos (MGM), lo que permite que los parámetros estimados sean consistentes y gocen de normalidad asintótica, siempre y cuando las variables sean estacionarias (Hansen, 1982; Arellano \& Bover 1995; Abrigo \& Love, 2016). Respecto a la elección de retardos del modelo, se usan los criterios de selección y momentos consistentes de los modelos MGM (análogos a los criterios de información de Akaike y Schwarz) propuestos por Andrews y Lu (2001) a partir del trabajo de Hansen (1982). 
Una vez que el modelo es estimado y validado, es factible efectuar una versión en panel del test de causalidad en el sentido de Granger (1969) entre las variables endógenas del modelo (test disponible gracias a los desarrollos de Abrigo y Love (2016)). Así, al considerar como ejemplo un modelo con dos variables endógenas representado en las expresiones (2) y (3):

$$
\begin{gathered}
Y_{c t}^{1 *}=\left(a_{11}^{1} Y_{c t-1}^{1 *}+\cdots+a_{11}^{p} Y_{c t-p}^{1 *}\right)+\left(a_{12}^{1} Y_{c t-1}^{2 *}+\cdots+a_{12}^{p} Y_{c t-p}^{2 *}\right)+v_{c t}^{1 *} \\
Y_{c t}^{2 *}=\left(a_{21}^{1} Y_{c t-1}^{1 *}+\cdots+a_{21}^{p} Y_{c t-p}^{1 *}\right)+\left(a_{22}^{1} Y_{c t-1}^{2 *}+\cdots+a_{22}^{p} Y_{c t-p}^{2 *}\right)+v_{c t}^{2 *}
\end{gathered}
$$

Se dice que la variable $Y_{c t}^{1 *}$ causa en el sentido de Granger a la variable $Y_{c t}^{2 *}$ si al menos uno de los valores pasados de $Y_{c t}^{1 *}$, es decir $Y_{c t-1}^{1 *}, \ldots, Y_{c t-p}^{1 *}$, incluidos en el modelo de la expresión (3) es un predictor estadísticamente significativo del valor presente de $Y_{c t}^{2 *}$ incluso cuando en el modelo se incluyen los retardos de esta última variable, es decir $Y_{c t-1}^{2 *}, \ldots, Y_{c t-p}^{2 *}$. En otras palabras, se dice que $Y_{c t}^{1 *}$ causa en el sentido de Granger a $Y_{c t}^{2 *}$ si al estimar el modelo de la expresión (3) se rechaza la hipótesis nula de que ningún coeficiente asociado a los retardos $Y_{c t-1}^{1 *}, \ldots, Y_{c t-p}^{1 *}$ es estadísticamente significativo, es decir se rechaza $H_{0}: a_{21}^{1}=\cdots=a_{21}^{p}=0$. Análogamente, se dice que $Y_{c t}^{2 *}$ causa en el sentido de Granger a $Y_{c t}^{1 *}$ si al estimar el modelo de la expresión (2) se rechaza la hipótesis nula $H_{0}: a_{12}^{1}=\cdots=$ $a_{12}^{p}=0$. Por su parte, si al mismo tiempo se rechazan las dos hipótesis nulas planteadas para los modelos (2) y (3), se deduce que ambas variables son endógenas y relevantes para el sistema, aunque la causalidad no puede ser plenamente aceptada pues podría existir una tercera variable omitida que influya sobre ambas.

Además de la causalidad en el sentido de Granger, con el modelo PVAR es posible obtener funciones de impulso respuesta (FIR) con las que se estima el efecto que tiene un shock en cada una de las variables endógenas sobre las demás variables. Tales funciones son adecuadas si no existe correlación entre los errores de las variables del sistema, es decir, si la matriz varianza-covarianza $\Sigma=$ $E\left[V_{c t} V_{c t}^{T}\right]$ asociada al vector de errores $V_{c t}$ es diagonal. Sin embargo, tras estimar un modelo PVAR esa matriz usualmente no es diagonal, es decir $\operatorname{Cov}\left[v_{c t}^{i} v_{c t}^{j}\right] \neq 0$. Para resolver tal limitante se puede transformar linealmente al vector de errores $V_{c t}$ pre-multiplicándolo por el inverso de una matriz diagonal inferior (con elementos unitarios en la diagonal) $L$ obtenida de la descomposición de Cholesky bajo la que se sabe que $\Sigma=L L^{T}$ (dado que la matriz de varianza-covarianza es simétrica y definida positiva), obteniéndose así un vector de errores transformados $U_{c t}=L^{-1} V_{c t}$ cuyos elementos no están correlacionados entre sí pues su matriz de varianza-covarianza asociada es igual a la identidad:

$$
E\left[U_{c t} U_{c t}^{T}\right]=E\left[L^{-1} V_{c t} V_{c t}^{T}\left(L^{-1}\right)^{T}\right]=L^{-1} \Sigma\left(L^{-1}\right)^{T}=I
$$

Dicha no-correlación permite estimar funciones impulso-respuesta para un modelo premultiplicado por la matriz $L^{-1}$, transformación que provoca que el orden de las variables en el modelo indique un diferente grado de endogeneidad, siendo la primera variable la menos endógena y la última variable la más endógena (Tsay, 2005).

Finalmente, tras estimar las funciones de impulso-respuesta, se puede efectuar la descomposición de varianza del error de predicción del modelo PVAR, lo que permite revisar cómo cambian las variables más endógenas ante shocks en las variables más exógenas, considerando la acumulación de efectos en el tiempo (Love \& Zicchino, 2006).

Por medio de la estimación de un modelo PVAR bajo las condiciones que se acaba de explicar, y en especial con la aplicación del test de causalidad de Granger, es factible estimar si son estadísticamente significativas las interacciones entre la producción, el subempleo, la explotación laboral y los balances comerciales de las diferentes actividades económicas dentro de un país periférico que mantiene relaciones comerciales con el resto del mundo. Aquí interesa, sobre todo, que se pueda 
identificar alguna evidencia de que el subempleo y la tasa de explotación laboral causan en el sentido de Granger a los déficits comerciales, lo que daría cierto respaldo a la hipótesis de que los capitales reguladores periféricos buscan ventajas absolutas de costo por medio de la sobreexplotación laboral (a más de la sobreexplotación natural que se tomaría en cuenta al incluir actividades extractivistas en el modelo). A su vez, con la estimación de las funciones impulso-respuesta considerando el orden de endogeneidad producción-subempleo-explotación laboral-balances comerciales (sugerido desde la motivación teórica de la sección 2) resulta factible evaluar si entre las variables mencionadas existe alguna dinámica de carácter cíclico, lo que reforzaría la hipótesis de que la forma en la que los países de la periferia capitalista se integran a la competencia real internacional genera una dinámica cíclica a nivel interno.

\section{Caso de estudio: el capitalismo periférico ecuatoriano.}

\subsection{Algunas tendencias históricas-cíclicas del capitalismo ecuatoriano.}

El Ecuador puede tomarse como un ejemplo típico de un país capitalista periférico cuya inserción en la competencia real del capitalismo internacional parece generar en su economía interna un comportamiento cíclico en donde se combina la sobreexplotación laboral en actividades enfocadas a sobre todo en productos primarios (p.ej. exportaciones bananeras) con la sobreexplotación natural que emerge de actividades extractivistas (p.ej. exportaciones petroleras). Toda esta dinámica parece generar ciclos de mediana y larga duración en la producción, el subempleo, la explotación laboral y los balances comerciales.

Una muestra del potencial comportamiento cíclico del capitalismo periférico ecuatoriano se evidencia en el gráfico 2, el que presenta una sucesión de épocas de crecimiento económico acelerado y otras de crecimiento ralentizado (e incluso de decrecimiento) según información histórica oficial del Banco Central del Ecuador (BCE). Por ejemplo, durante el primer boom petrolero vivido por el país entre 1972-1978 el producto interno bruto per cápita tuvo en promedio una tasa de crecimiento real anual de casi $5 \%$, tras lo que el crecimiento promedio se quedaría estancado en menos de $1 \%$ en todo el período 1979-1999 (etapa en donde se combinó tanto la década neoliberal de los años 80 con la crisis financiera de los 90). Luego vendría un segundo boom petrolero que, entre los períodos 2000-2006 y 2007-2013, promovería un crecimiento del producto per cápita real de alrededor de 2,5\%, que se agotó con la caída de los precios del petróleo de fines de 2014, dando inicio a una etapa de estancamiento económico del país que persiste hasta 2019.

Gráfico 2. Promedio de tasas de crecimiento real del PIB, PIB per cápita y población (Ecuador, 19652019).

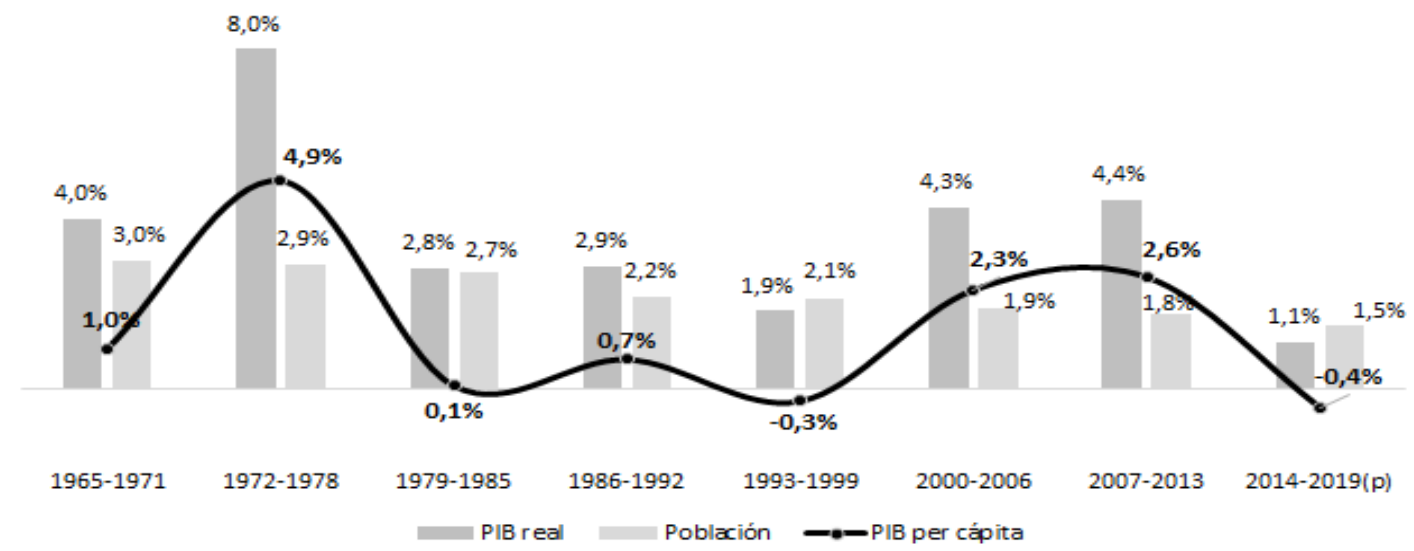

Nota: Para 2019 se usa una previsión oficial.

Fuente: BCE. Elaboración a partir del trabajo de Acosta y Cajas-Guijarro (2018). 
Así como la producción parece mostrar un comportamiento cíclico de medio a largo plazo en términos agregados, también es posible identificar un potencial comportamiento cíclico en la dinámica del subempleo o empleo no adecuado. Por ejemplo, en el Gráfico 3 se presenta, por un lado, una estimación histórica de la tasa de subempleo obtenida a partir de las fuentes y métodos propuestos en el trabajo de Noroña y Cajas-Guijarro (2014, anexo A.2) y, por otro lado, se presenta la tasa oficial de empleo no adecuado del Instituto Nacional de Estadísticas y Censos del Ecuador (INEC). Cabe aclarar que por toda la diversidad de fuentes utilizadas, las estimaciones históricas de Noroña y Cajas-Guijarro (2014) deben tomarse únicamente en términos referenciales y no como estimaciones definitivas. En el mencionado Gráfico 3 puede notarse sobre todo el aumento del subempleo en las décadas de los 80, 90 e incluso hasta mediados de los 2000, quizá como respuesta a todo el deterioro laboral vivido en tiempos neoliberales y como resultado de la crisis financiera. Luego se nota una reducción del empleo no adecuado entre 2007-2014, coincidiendo con el momento más intenso del segundo boom petrolero. Posteriormente, el empleo no adecuado ha ido creciendo desde 2015 hasta el primer semestre de 2019 como consecuencia del estancamiento económico persistente que vive el país en dicho período.

\section{Gráfico 3. Estimación histórica de la tasa de subempleo-empleo no adecuado (Ecuador, 1950-2019).}

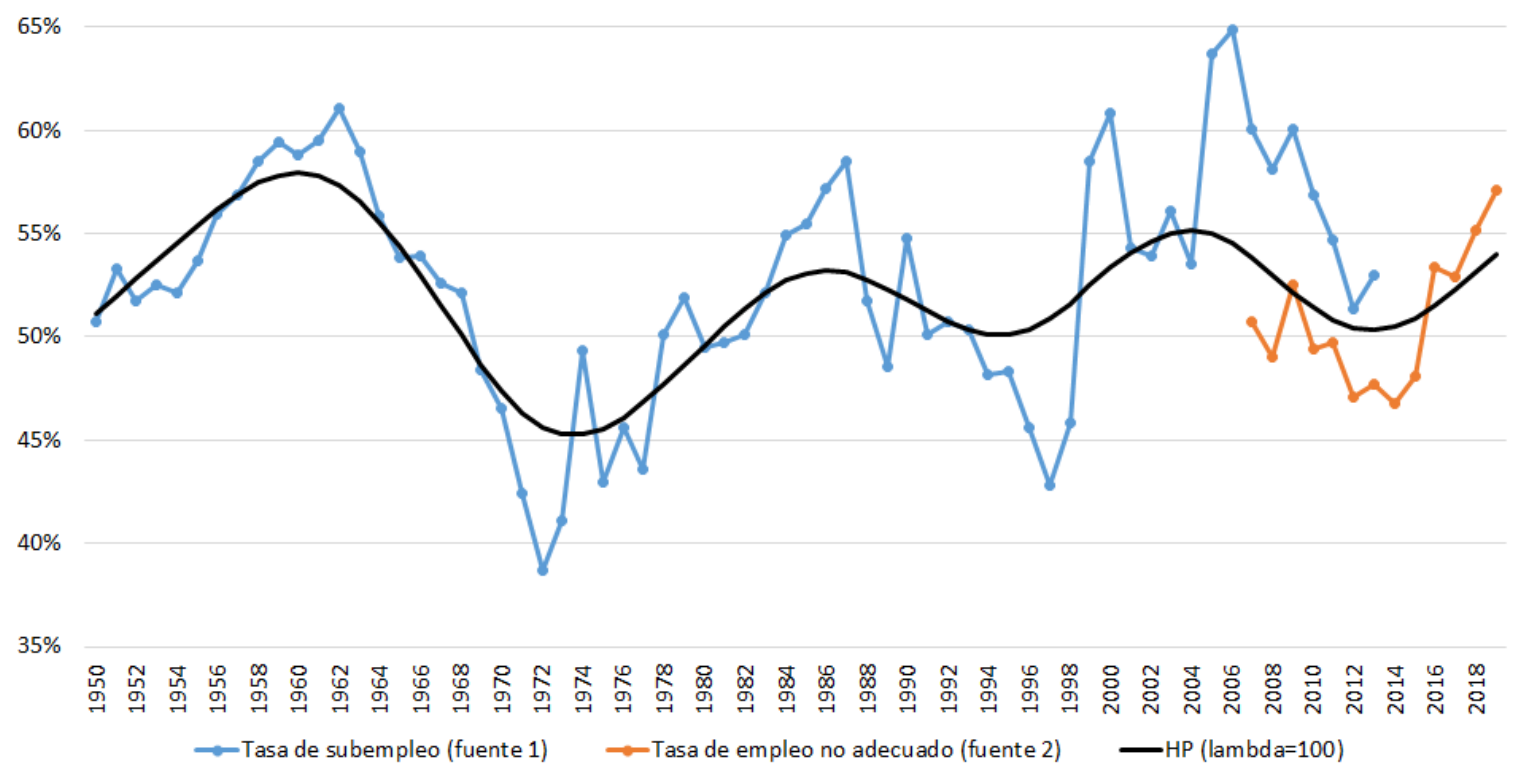

Nota: Para 2019 se usa dato oficial al primer semestre del año.

HP: Filtro Hodrick-Prescott con factor de suavizamiento lambda $=100$.

Fuente 1: Estimaciones del trabajo de Noroña y Cajas-Guijarro (2014) a partir del BCE y del INEC.

Fuente 2: Tasa de empleo no adecuado oficial del INEC hasta primer semestre de 2019.

Elaboración propia.

Sobre la dinámica de la tasa de explotación laboral, ésta puede aproximarse por medio de la pugna distributiva descrita en la ratio entre excedente bruto de explotación / remuneraciones a los asalariados, que se toma como proxy de una ratio ganancias/salarios. Siendo más rigurosos, el excedente bruto de explotación recoge tanto a las ganancias del capital como a los ingresos obtenidos por trabajadores por cuenta propia de la venta de sus negocios. De todas formas, ante la carencia de información más detallada, se asume que la participación de las ganancias del capital es mayoritaria. Para una discusión metodológica del uso de la ratio excedente bruto de explotación / remuneraciones a los asalariados como proxy de la tasa de explotación, ver Noroña y Cajas-Guijarro (2014).

A través de las estimaciones históricas y la información oficial de esta variable presentadas en el Gráfico 4 se evidencia un fuerte deterioro de los salarios con respecto a las ganancias especialmente en 
las décadas de los 80 y 90 (llegando hasta a una relación de 5 a 1), lo que tiene cierta correspondencia con el deterioro laboral y salarial propios de épocas neoliberales y de crisis. Después se observa una recuperación relativa de los salarios en los años 2000, aunque la misma parece haberse estancado entre 2015-2017. Resultado de este comportamiento, parecería que la explotación laboral muestra un solo gran ciclo que recoge la transición entre etapa neoliberal, crisis financiera y segundo boom petrolero.

\section{Gráfico 4. Estimación histórica de la ratio excedente bruto de explotación / remuneración a los asalariados (EBE/REM) (Ecuador, 1950-2017).}

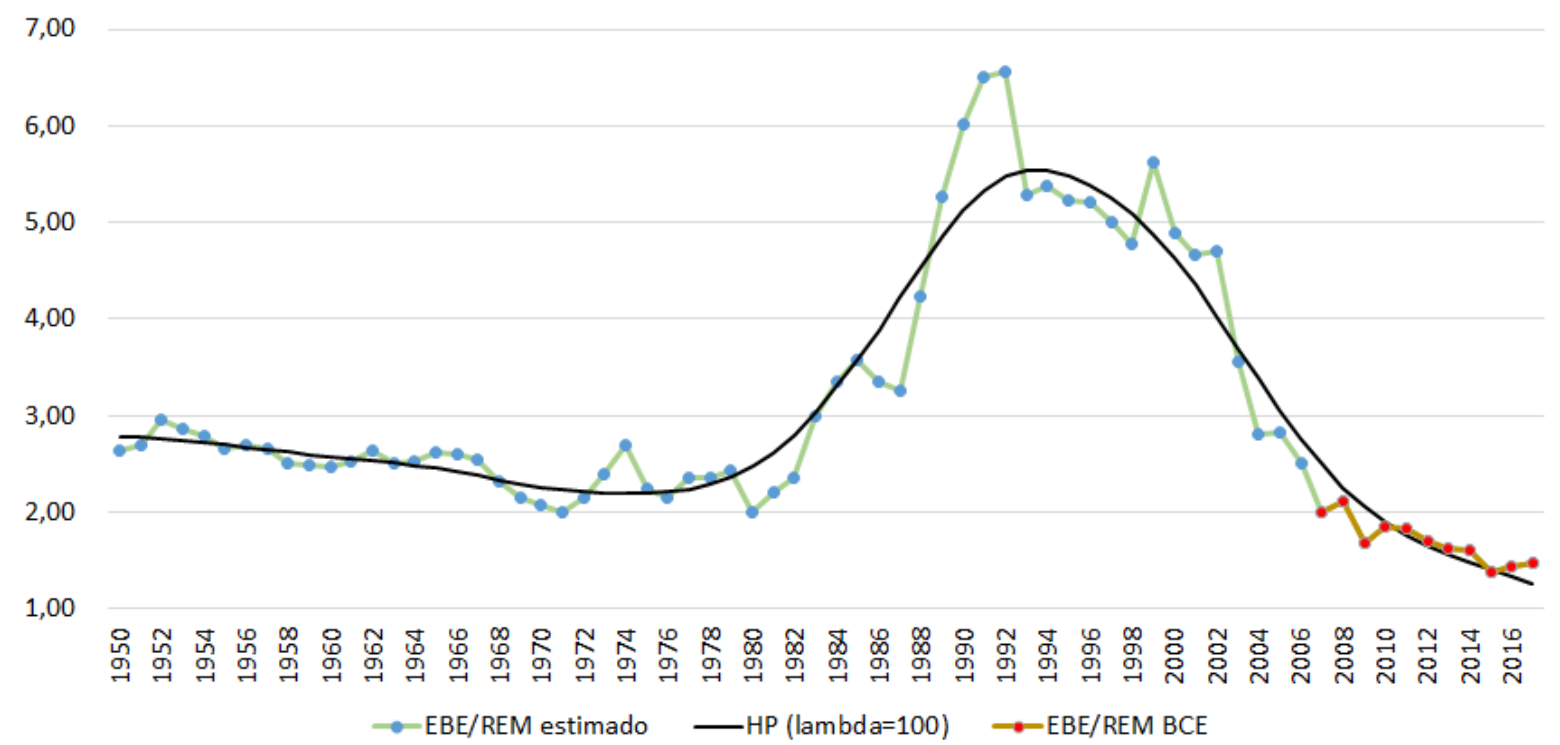

HP: Filtro Hodrick-Prescott con factor de suavizamiento lambda $=100$.

Fuente 1: Estimaciones del trabajo de Noroña y Cajas-Guijarro (2014) a partir de información del BCE y del INEC entre 1950-2006. Fuente 2: Tasa oficial del BCE entre 2007-2017.

Elaboración propia.

En cuanto a los balances comerciales, una forma de revisar su evolución histórica es por medio de la ratio importaciones / exportaciones, que se presenta en el Gráfico 5 y también parece mostrar comportamientos cíclicos de larga duración resaltando los importantes superávits del primer boom petrolero y los déficits que vendrían después con la crisis de los años 80 y 90. En cambio, el segundo boom petrolero no dejó al país superávits comerciales tan importantes como el primero, en especial porque en el período 2007-2013 aumentó la dependencia del país en la importación de medios de producción tal como indica el aumento del peso de las importaciones de insumos y bienes de capital con respecto al PIB evidenciado en dichos años (Por ejemplo, mientras que en 2007 la ratio entre importaciones de materias primas / PIB fue de 8,8\% para 2013 llegó a 12,4\%; en cambio la ratio entre importaciones de bienes de capital / PIB entre 2007-2013 aumentó de 6,9\% a 10,5\%, todo según información oficial del BCE). Es decir, a diferencia del primer boom petrolero, en el segundo boom la expansión económica exacerbó las importaciones antes que generar fuertes superávits comerciales.

Las tendencias históricas arriba descritas parecen brindar argumentos a favor de que al interior del capitalismo periférico ecuatoriano hay importantes comportamientos cíclicos de mediano-largo plazo en la producción, el subempleo (o empleo no adecuado), la explotación laboral y los balances comerciales (Para más detalles sobre las tendencias históricas-cíclicas del capitalismo ecuatoriano se puede revisar los trabajos de Noroña y Cajas-Guijarro (2014) y Cajas-Guijarro y Acosta (2017)). Ahora, para definir si tales tendencias históricas-cíclicas del capitalismo ecuatoriano poseen algún vínculo con la forma como el país se inserta en el proceso de competencia real internacional, es necesario revisar 
con más detalle las condiciones concretas en las que las actividades económicas ecuatorianas participan del comercio internacional y de las condiciones económicas locales.

Gráfico 5. Ratio histórica de importaciones/exportaciones (M/X) (Ecuador, 1950-2018).

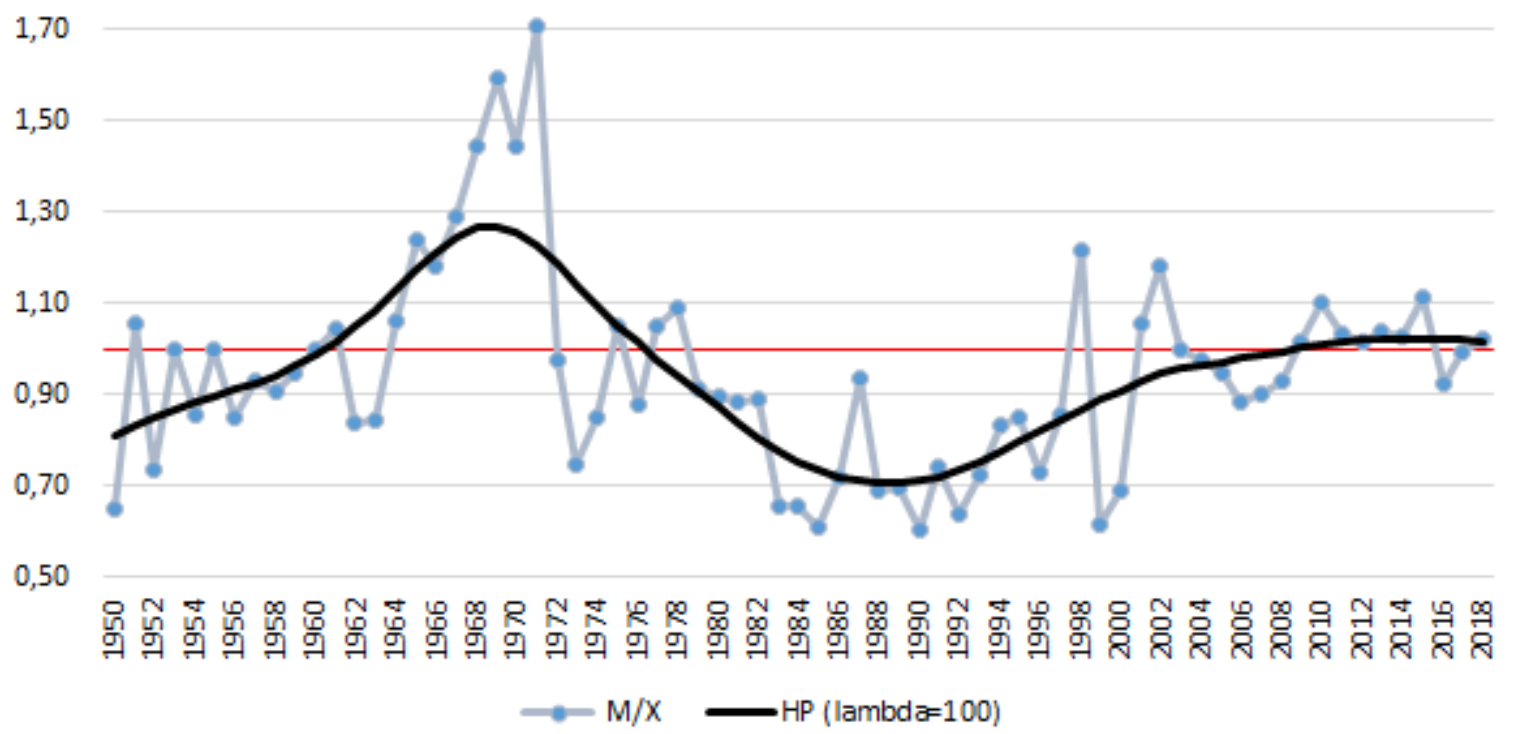

Nota: Línea roja horizontal indica equilibrio comercial $(\mathrm{X}=\mathrm{M})$

HP: Filtro Hodrick-Prescott con factor de suavizamiento lambda $=100$.

Fuente: BCE. Elaboración propia.

\subsection{Datos y tendencias sectoriales ecuatorianas para el período 2007-2016.}

La hipótesis sobre la potencial interacción cíclica entre producción, subempleo, explotación laboral y balances comerciales (que teóricamente se ha argumentado que proviene de la búsqueda por parte de la periferia capitalista de ventajas absolutas de costo a través de la sobreexplotación laboral-natural) puede ser contrastada para el caso ecuatoriano para el período 2007-2016 a nivel de actividades económicas. Tal período ha sido seleccionado porque brinda la mayor disponibilidad de información detallada y consistente a nivel de actividades económicas al momento de escribir este trabajo, además de que captura tanto el punto más elevado del segundo boom petrolero del país como el inicio del posterior estancamiento económico (es decir, captura el último cambio de ciclo de mediano-largo plazo del capitalismo ecuatoriano). Las principales fuentes de información consultadas son las Tablas oferta Utilización (TOU) del BCE, la Encuesta Nacional de Empleo y Desempleo Urbano-Rural (ENEMDU) del INEC, y la base de datos de comercio de Naciones Unidas (COMTRADE).

La información fue armonizada usando las correspondencias de la clasificación industrial internacional uniforme (CIIU) entre las versiones 3 y 4 y de éstas con la versión 2 de la clasificación uniforme de comercio internacional (CUCI). De esa armonización ha sido posible obtener un panel de datos compuesto por 43 actividades económicas observadas durante 10 años. Para ese panel de 430 observaciones se obtienen las siguientes variables en concordancia tanto con la reflexión teórica de la sección 2 como con las tendencias históricas-cíclicas presentadas en la subsección 4.1: el PIB por actividad económica (PIB), como proxy de la dinámica de la producción y del ingreso; la ratio entre empleo no adecuado y población económicamente activa (ENA/PEA) (usando las categorías de empleo más actuales propuestas por el INEC), como proxy de la proporción de trabajadores que sufren de sobreexplotación y, por tanto, se ubican en el subempleo; la ratio entre excedente bruto de explotación y remuneraciones (EBE/REM) como proxy de la pugna distributiva entre ganancias y salarios; la ratio 
importaciones/exportaciones $(\mathrm{M} / \mathrm{X})$ como proxy del balance comercial del Ecuador en su comercio internacional con el resto del mundo. Dentro del empleo no adecuado el INEC incluye a los subempleados (quienes reciben un ingreso laboral menor al salario básico y/o trabajan una jornada menor a la legal y desean y pueden trabajar más horas), el empleo no remunerado y otro empleo no pleno (quienes reciben un ingreso laboral menor al salario básico y/o trabajan menos de la jornada legal pero no desean o no pueden trabajar más hora). Así, la categoría de empleo no adecuado del INEC sería lo más cercano a la intuición que convencionalmente se tiene de subempleados como aquellos trabajadores que reciben un salario por debajo del valor de su fuerza de trabajo.

Los gráficos 6 a 9 muestran los valores que toman estas variables para las diferentes actividades económicas considerando los años 2007 y 2016 como referencia.

Así, el Gráfico 6 indica que en 2016 las actividades de mayor producción dentro del panel de datos analizado son: extracción de petróleo; producción de banano, café y cacao; procesamiento de camarón; procesamiento de carne; cría de ganado; producción de otros productos químicos; fabricación de cemento; producción de productos de madera; silvicultura; acuicultura. De estas actividades, según el Gráfico 7 en 2016 la producción de banano, café y cacao, la cría de ganado, la silvicultura y la acuicultura tuvieron a más del $40 \%$ de su población económicamente activa en condiciones de empleo no adecuado. Por su parte, el Gráfico 8 muestra que justo estas cuatro actividades poseen una ratio explotación/salarios mayor a la unidad, siendo la silvicultura el caso más extremo en donde las ganancias del capital (y de los trabajadores por cuenta propia) son más de 42 veces mayores a las remuneraciones a los asalariados, seguida por la cría de ganado con 2,48 veces, la producción de banano, café y cacao con 2,3 veces y la acuicultura con 1,8 veces. Finalmente, el Gráfico 9 sugiere que en 2016 las cuatro actividades consideradas tuvieron superávits comerciales (ratio $\mathrm{M} / \mathrm{X}$ menor a la unidad), siendo el caso más destacado el superávit registrado para la producción de banano, café y cacao, seguido por la acuicultura.

En definitiva, de las tendencias analizadas se podría considerar que hay al menos cuatro actividades económicas ecuatorianas de tamaño relevante que podrían validar la hipótesis de que los capitales reguladores periféricos tienden a buscar ventajas absolutas de costo y obtener superávits comerciales por medio de la sobreexplotación laboral y la consecuente generación de empleo no adecuado (producción de banano, café y cacao, acuicultura, cría de ganado, acuicultura). A estas actividades se suma la extracción de petróleo que, evidentemente en el caso ecuatoriano, sostiene su ventaja absoluta de costo por medio de la sobreexplotación de la naturaleza a través del extractivismo. Este resultado brinda una motivación adicional para evaluar empíricamente la forma en que la competencia real internacional influye en las actividades económicas al interior de los países periféricos capitalistas como el Ecuador. 
Gráfico 6. PIB por actividad económica (millones de dólares).

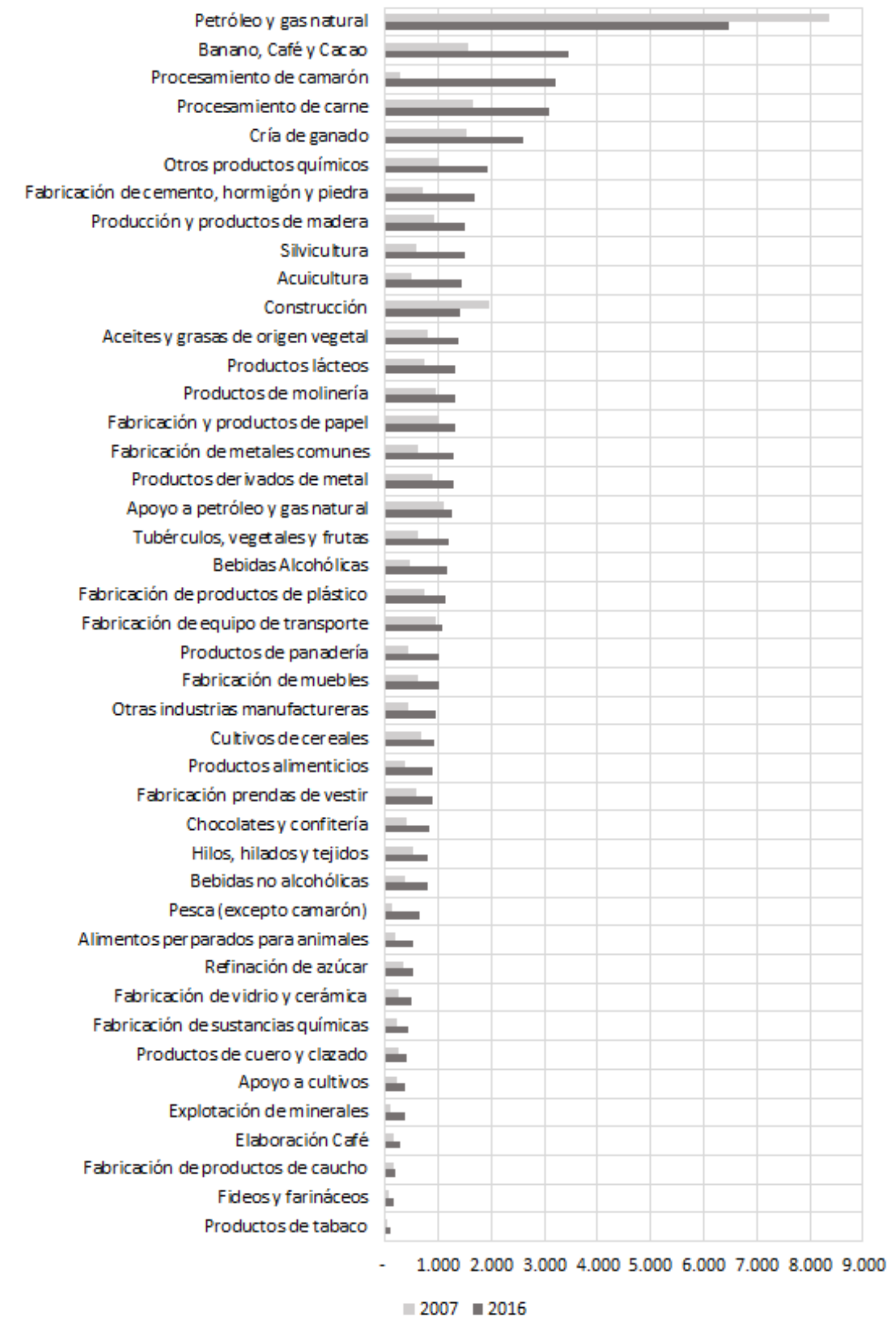

Fuente: TOU- BCE. Elaboración propia. 
Gráfico 7. Tasa de empleo no adecuado por actividad económica (\% de la PEA).

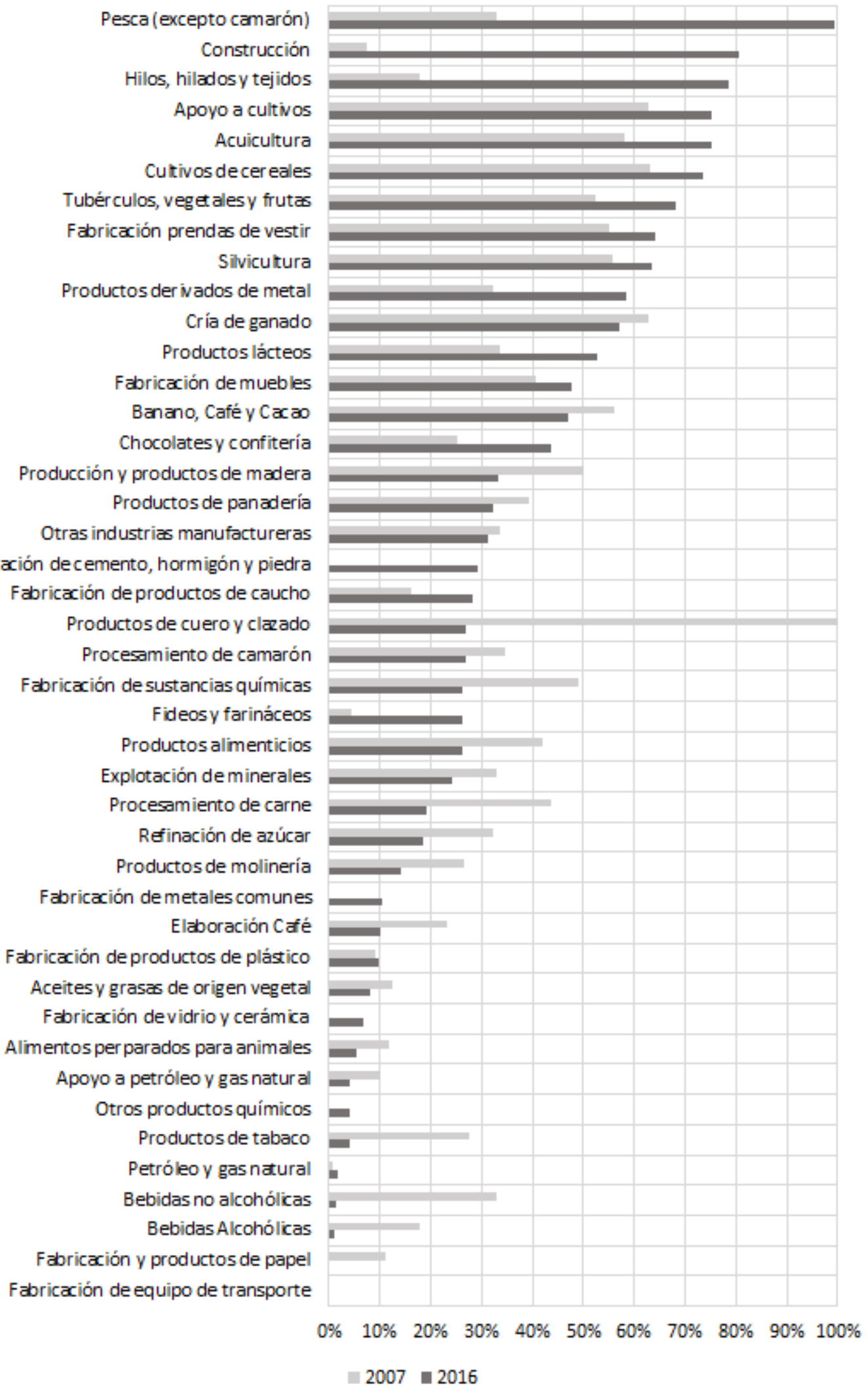

Fuente: ENEMDU-INEC. Elaboración propia. 
Gráfico 8. Ratio excedente bruto de explotación / remuneraciones a asalariados por actividad económica (escala logarítmica).

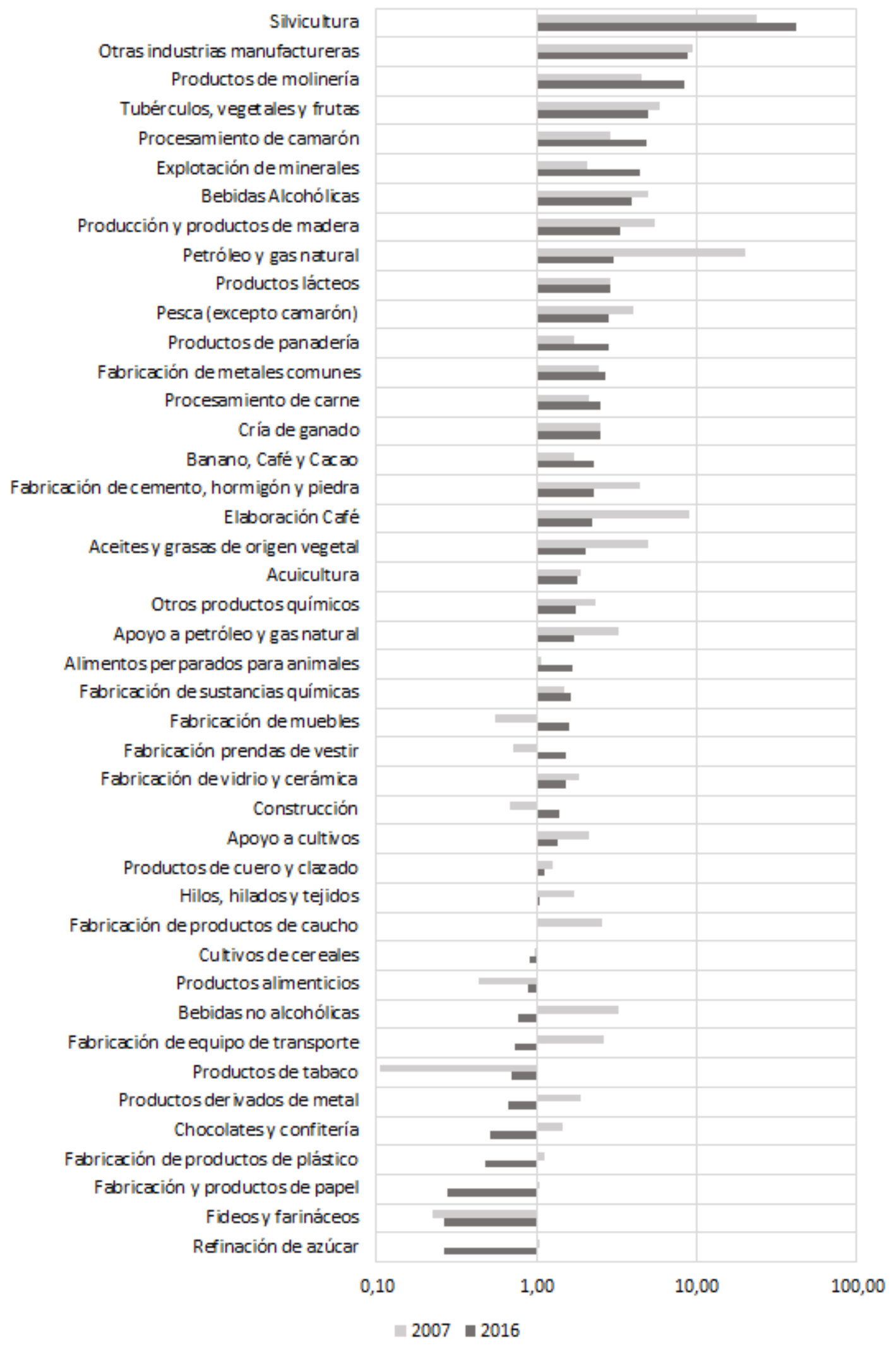

Fuente: TOU- BCE. Elaboración propia. 
Gráfico 9. Ratio importaciones / exportaciones por actividad económica (escala logarítmica).

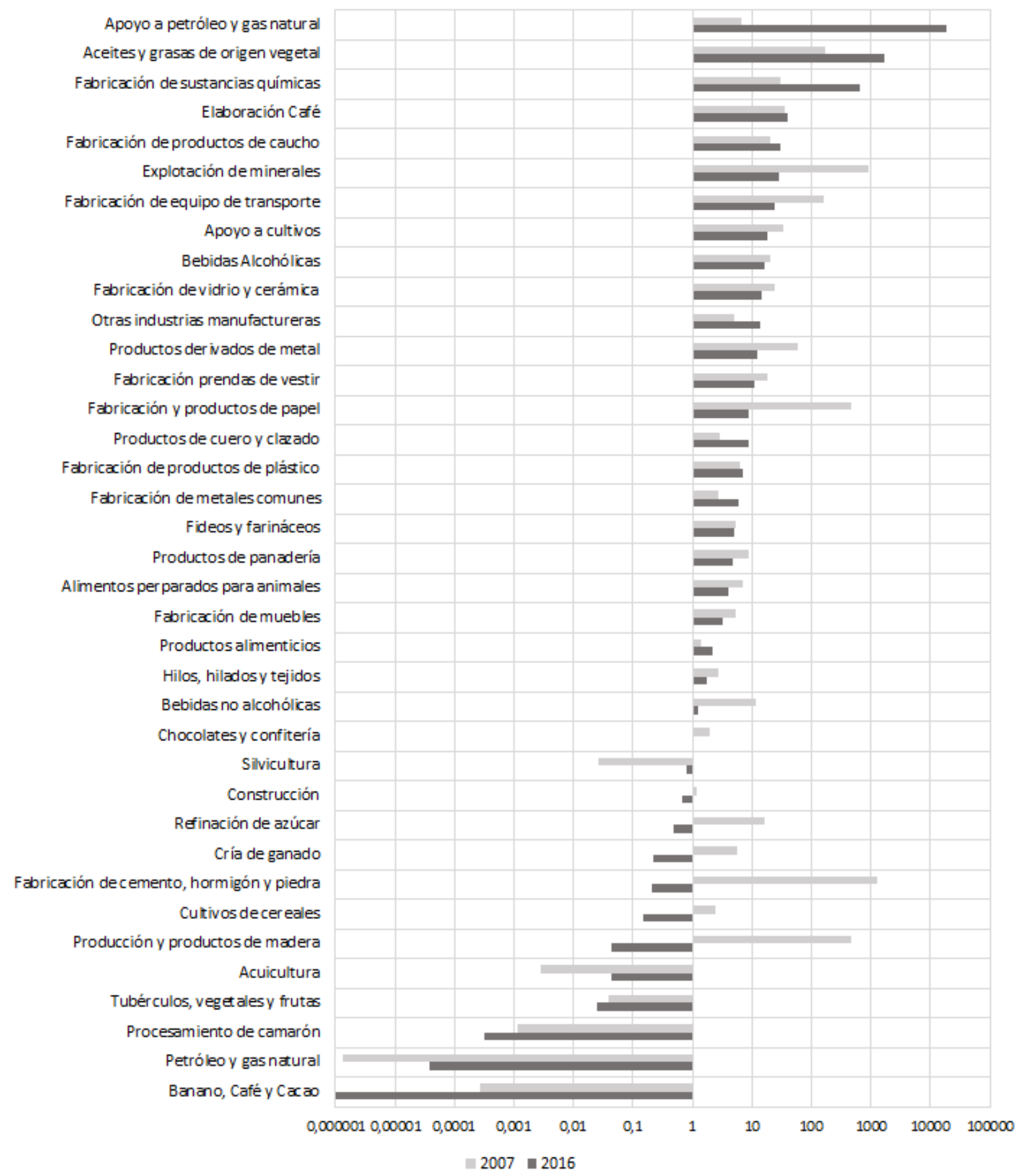

Nota: Se omiten actividades que no presentan exportaciones o importaciones en algún año.

Fuente: COMTRADE. Elaboración propia.

\subsection{Estimación del modelo PVAR al caso ecuatoriano: resultados y discusión.}

Considerando la posibilidad de un comportamiento cíclico agregado del capitalismo periférico ecuatoriano así como de la existencia de actividades económicas que basan su ventaja absoluta de costo a través de la sobreexplotación laboral-natural, ahora se busca una evidencia más general de un potencial vínculo cíclico entre producción, subempleo (o empleo no adecuado), explotación laboral y superávits-déficits comerciales en el capitalismo ecuatoriano a nivel de actividades económicas causado por la inserción del país en el proceso de competencia real internacional. Para ello, a continuación se 
aplica la metodología propuesta en la sección 3, es decir, se estima un modelo PVAR sobre el panel de datos previamente descrito y compuesto por 43 actividades económicas para el período 2007-2016.

Así, en primer lugar, los test de Levin-Lin-Chu y Hadri mostraron que la tasa de empleo no adecuado (de ahora en adelante descrita como ENA/PEA) y la ratio excedente bruto de explotación/remuneraciones a los asalariados (EBE/REM) son individualmente estacionarias en nivel, mientras que el PIB por actividad económica (PIB) y la ratio importaciones / exportaciones $(\mathrm{M} / \mathrm{X})$ son individualmente estacionarias en su logaritmo (es decir $\ln P I B$ y $\operatorname{lnM} / \mathrm{X}$ son individualmente estacionarias). Sin embargo, conjuntamente las variables revelaban la existencia de alguna raíz unitaria (ver anexo A.1). Por ello a todas las variables se aplicó una primera diferencia (notada como d.) para asegurar que el modelo PVAR se estima sobre variables estacionarias y se mitigue cualquier posibilidad de regresiones espurias o resultados explosivos. Al trabajar con un modelo en diferencias, los resultados pueden considerarse válidos en el corto plazo (Melguizo, 2015).

En segundo lugar, como se emplea la descomposición de Choleski para estimar desde los resultados del modelo PVAR funciones impulso-respuesta y descomposición de varianza del error de predicción, cabe definir el orden de las variables en el modelo, de la más exógena a la más endógena. Dicho orden corresponderá exactamente al caso explicado al final de la subsección 2.3.2 en donde se mencionó que ante un potencial shock exógeno sobre la producción causado, por ejemplo, por cambios autónomos en la demanda agregada, se esperaría un cambio en el subempleo o empleo no adecuado, luego un consecuente cambio en la ratio de explotación/salarios y, al final y a causa de la tendencia a la búsqueda de ventajas absolutas de costo a través de la sobreexplotación laboral, se daría un cambio en el balance comercial. Por tanto, el orden de variables a aplicar en el modelo PVAR es: d.lnPIB ("producción"), d.ENA/PEA ("subempleo"), d.EBE/REM ("explotación laboral") y d.lnM/X ("balance comercial"). Una vez establecido este orden de variables, la aplicación de las respectivas pruebas determina que la mejor opción es incluir en el modelo autorregresivo un solo rezago, lo que es conveniente también por el limitado número de observaciones en términos temporales (ver Anexo A.2).

A partir de todos estos criterios, el Cuadro 1 recoge la estimación de un modelo PVAR con un rezago $(p=1)$, incluyendo la primera diferencia de todas las variables endógenas antes descritas y presentadas en su correspondiente orden. Aquí cabe resaltar la significancia estadística de todos los parámetros estimados a un $99 \%$ de nivel de confianza, excepto en la interacción del retardo del "balance comercial" (d.lnM/X) hacia la "explotación laboral" (d.EBE/REM). También cabe indicar que el modelo es estable, como indican los valores propios ubicados dentro del círculo unitario (ver Anexo A.3). Por su parte, la prueba de Granger presentada en el Cuadro 2 evidencia que todas las variables consideradas en el modelo son estadísticamente relevantes, a la vez que existen múltiples retroalimentaciones significativas. De esta prueba cabe destacar un resultado llamativo: hay evidencia de que la "explotación laboral" (d.EBE/REM) causa en el sentido de Granger al "balance comercial" $(\mathrm{d} . \ln \mathrm{M} / \mathrm{X})$ pero no al revés; es decir, no hay retroalimentación directa entre ambas variables.

Este resultado podría interpretarse como que la "explotación laboral" causa - en el sentido de Granger - al "balance comercial" pero no viceversa. Tal causalidad en una sola dirección refuerza la intuición de que la ventaja absoluta de costo basada en la sobreexplotación laboral influye directamente en el balance comercial de las actividades del capitalismo periférico ecuatoriano. En cambio, la relación inversa no se da quizá porque las condiciones laborales de sobreexplotación posiblemente dependen más de aspectos estructurales internos de la economía ecuatoriana - incluyendo la propia situación de la pugna entre clases sociales locales - que de aspectos externos.

Una vez estimado y validado el modelo PVAR, se puede estimar las funciones de impulsorespuesta (FIR) transitorias y acumuladas aplicando la descomposición de Cholesky, tal como se indicó en la Sección 3. Dicha estimación se presenta en los gráficos 10 a 13. Casi en todas las funciones impulso-respuesta transitorias y acumuladas, a lo largo de diez períodos de proyección, parece identificarse una retroalimentación cíclica, pues si bien en un período descienden radicalmente, no tardan en regresar a su valor pasado o hasta superarlo en períodos siguientes, permitiendo así entrever la compleja lógica de la difusión -y retroalimentación- de shocks entre las variables analizadas. Este 
resultado parece favorable a la motivación teórica presentada en la sección 2 donde se sugiere que la competencia real internacional y la búsqueda de ventajas absolutas de costo por medio de la sobreexplotación laboral-natural tienden a generar un comportamiento cíclico al interior de una sociedad capitalista periférica (A partir de las sugerencias de Apostolakis y Papadopoulos (2019) y Brana, Djibenou y Prat (2012), para evaluar cuán robustos son los resultados cíclicos de las funciones impulso-respuesta, hemos estimado el modelo PVAR con todos los órdenes posibles de las variables endógenas. De dicha prueba de robustez hemos encontrado que prácticamente en todos los ordenamientos alternativos rige un comportamiento cíclico. Estos resultados pueden solicitarse a los autores del artículo vía correo electrónico). Asimismo, este resultado suma respaldo a favor de la potencial existencia de tendencias cíclicas en el capitalismo ecuatoriano, aunque por la forma del modelo estimado la dinámica cíclica corresponde a un corto plazo (y no necesariamente al largo plazo, como sí parece suceder en las tendencias presentadas en la subsección 4.1). Cabe aclarar que es necesario un trabajo estadístico más profundo para reforzar la existencia de ciclos de medio y largo plazo en el capitalismo ecuatoriano, tema que se sale de los límites de este trabajo y se deja para una investigación futura. Un primer intento, bastante preliminar, puede encontrarse en Noroña y CajasGuijarro (2014).

Cuadro 1. Estimación de parámetros del modelo PVAR.

\begin{tabular}{ccccc}
$\boldsymbol{V A R} \boldsymbol{R} \boldsymbol{A B L E S}$ & $\begin{array}{c}\text { d.InPIB } \\
\text { "producción" }\end{array}$ & $\begin{array}{l}\text { d.ENA/PEA } \\
\text { "subempleo" }\end{array}$ & $\begin{array}{c}\text { d.EBE/REM } \\
\text { "explotación } \\
\text { laboral" }\end{array}$ & $\begin{array}{c}\text { d.InM/X } \\
\text { "balance comercial" }\end{array}$ \\
\hline $\begin{array}{c}\text { d.InPIB(-1) } \\
\text { "producción en t-1" }\end{array}$ & $-1.038^{* * *}$ & $\begin{array}{c}0.0202^{* * *} \\
(0.0471)\end{array}$ & $\begin{array}{c}-5.718^{* * *} \\
(0.00453)\end{array}$ & $\begin{array}{c}2.352^{* * *} \\
(0.226)\end{array}$ \\
\hline d.ENA/PEA(-1) & $-1.598^{* * *}$ & $-0.485 * * *$ & $-36.13^{* * *}$ & $8.417 * * *$ \\
"subempleo en t-1" & $(0.277)$ & $(0.0246)$ & $(5.322)$ & $(1.366)$
\end{tabular}

\begin{tabular}{ccccc}
\hline d.EBE/REM(-1) & $0.0566^{* * *}$ & $0.00332 * * *$ & $-0.585^{* * *}$ & $-0.214^{* * *}$ \\
“explotación laboral en t-1” & $(0.00774)$ & $(0.000949)$ & $(0.0775)$ & $(0.0515)$
\end{tabular}

\begin{tabular}{ccccc}
\hline $\mathrm{d} . \operatorname{lnM} / \mathrm{X}(-1)$ & $-0.0739 * * *$ & $0.00495 * * *$ & -0.233 & $-0.523 * * *$ \\
"balance comercial en t-1" & $(0.0138)$ & $(0.00144)$ & $(0.142)$ & $(0.0756)$
\end{tabular}

\footnotetext{
\begin{tabular}{ccccc}
\hline Observaciones & 400 & 400 & 400 & 400 \\
\hline (1) d. indica una primera diferenciación, In indica la aplicación de un logaritmo natural &
\end{tabular}

(1) d. indica una primera diferenciación, In indica la aplicación de un logaritmo natural.

(2) Errores estándar en paréntesis

(3) Significatividad $* * * \mathrm{p}<0.01, * * \mathrm{p}<0.05, * \mathrm{p}<0.1$

(4) Las columnas indican los parámetros de cada ecuación del modelo PVAR.

Fuente: TOU- BCE; ENEMDU-INEC; COMTRADE. Elaboración y estimación propias.

Además de las FIR, y manteniendo el orden de variables sustentado en la motivación teórica de la sección 2, es posible estimar las funciones de descomposición de varianza del error de predicción (FDVE), que estiman la variación porcentual que se da en una variable a causa del shock en otra, tomando en cuenta los efectos acumulados del tiempo (Love \& Zicchino, 2006). Así, la Tabla 2 muestra un shock exógeno sobre la "producción" (d. $\ln \mathrm{PIB}$ ) en $t=1$ y luego su difusión en el resto de variables, provocando que, para $t=10$, la "explotación laboral" (d.EBE/REM) explique un $31 \%$ de las variaciones de la "producción", tal como sucede en el "subempleo" (d.ENA/PEA), que llega a explicar también un
} 
$31 \%$ de la variación de la "producción" en $t=10$. Por su parte, el "balance comercial" (d.lnM/X) termina explicando solo un $6 \%$ de las variaciones de la "producción".

Cuadro 2. Causalidad de Granger en el modelo PVAR.

\begin{tabular}{|c|c|c|c|c|}
\hline \multicolumn{5}{|c|}{ Test de Wald de causalidad de Granger en PVAR } \\
\hline Variable de ecuación & Variable excluida & chi2 & gl & Prob $>$ chi2 \\
\hline d.lnPIB & d.ENA/PEA|"subempleo" & 33.233 & 1 & 0.000 \\
\hline \multirow[t]{3}{*}{ "producción" } & d.EBE/REM|"explotación laboral" & 53.522 & 1 & 0.000 \\
\hline & d. $\operatorname{lnM} / \mathrm{X}$ | "balance comercial" & 28.642 & 1 & 0.000 \\
\hline & Todas las variables & 99.473 & 3 & 0.000 \\
\hline d.ENA/PEA & d.lnPIB |"producción" & 20.005 & 1 & 0.000 \\
\hline \multirow[t]{3}{*}{ "subempleo" } & d.EBE/REM |"explotación laboral" & 12.217 & 1 & 0.000 \\
\hline & d.lnM/X |"balance comercial" & 11.722 & 1 & 0.001 \\
\hline & Todas las variables & 36.574 & 3 & 0.000 \\
\hline d.EBE/REM & d.lnPIB | "producción" & 67.465 & 1 & 0.000 \\
\hline \multirow[t]{3}{*}{ “explotación laboral" } & d.ENA/PEA | "subempleo" & 46.095 & 1 & 0.000 \\
\hline & d. $\operatorname{lnM} / \mathrm{X}$ | "balance comercial" & 2.700 & 1 & 1.000 \\
\hline & Todas las variables & 90.512 & 3 & 0.000 \\
\hline $\mathrm{d} \cdot \ln \mathrm{ln} / \mathrm{X}$ & d.lnPIB | "producción" & 108.091 & 1 & 0.000 \\
\hline \multirow[t]{3}{*}{ "balance comercial" } & d.ENA/PEA |"subempleo" & 37.983 & 1 & 0.000 \\
\hline & d.EBE/REM | "explotación laboral" & 17.250 & 1 & 0.000 \\
\hline & Todas las variables & 126.465 & 3 & 0.000 \\
\hline
\end{tabular}

Ho: La variable excluida no causa en el sentido de Granger a la variable de ecuación

Ha: La variable excluida causa en el sentido de Granger a la variable de ecuación

(1) Todas las variables se encuentran diferenciadas.

Fuente: TOU- BCE; ENEMDU-INEC; COMTRADE. Elaboración y estimación propias.

Por su parte, la Tabla 3 muestra como un shock en el "subempleo" es explicado mayoritariamente por sí mismo en los diez períodos de estimación, pues inicia en $t=1$ con un $98 \%$ de explicación y llega en $t=10$ con $76 \%$. Tan solo la "producción" adquiere cierta relevancia a partir de $t>5$ con un $13 \%$ de variación del "subempleo" explicada, lo que por cierto arrastra los efectos acumulados del shock sobre la propia "producción" descritos en la Tabla 2. Esto no ocurre con la "explotación laboral" y el "balance comercial" pues su porcentaje de explicación no excede el 3\% y 8\% respectivamente, en los diez períodos de estimación. Es decir, el "subempleo" es la variable más resistente ante los shocks exógenos de sí misma y del resto de variables, lo que podría plantear la hipótesis de que esta variable posee un carácter posiblemente más estructural y dependiente de las condiciones internas de la economía ecuatoriana. De hecho en Ecuador el subempleo es un problema histórico persistente, pues ya desde los años 50 absorbe a la mitad de la fuerza de trabajo, según información histórica de la CEPAL (Ver, por ejemplo, Tokman y García (1981)).

Respecto a un shock exógeno en la "explotación laboral", la Tabla 4 señala cómo en $t=1$ los efectos acumualdos del shock exógeno en la "producción" (Tabla 2) contribuyen en un 29\% a la variación explicada. Así, a partir de $t=2$ hasta $t=10$ existen fluctuaciones en el porcentaje de aportación de la "producción", pues pasa de un 38\% a un $29 \%$. Del mismo modo ocurre con el "subempleo" que inicia con una variación explicada del $20 \%$ (en parte por el shock exógeno anterior mencionado en la Tabla 3) y llega a ser de un $36 \%$ en $t=10$. Una vez más, el "balance comercial" tiene una variación de explicación baja de tan solo $3 \%$.

Finalmente, en la Tabla 5 se representa un shock exógeno en el "balance comercial", donde la variación explicada por la "producción" y la "explotación laboral" es de 14\% y 7\% respectivamente. 
Sin embargo, a partir de $t=2$ aumentan considerablemente hasta llegar a un $20 \%$ y $29 \%$ respectivamente; el mismo fenómeno ocurre con el "subempleo", que parte con un $0 \%$ de variación explicada en $t=2 \mathrm{y}$ llega a mostrar en $t=10$ una variación explicada de $32 \%$, incluso más fuerte que el shock exógeno del propio "balance comercial", que a lo largo de diez períodos de estimación pasa de un $79 \%$ a un 19\%.

Como resultado general de todas las estimaciones de las FDVE se sugiere que, a causa de las múltiples retroalimentaciones y dinámicas cíclicas de las variables consideradas, en el capitalismo ecuatoriano hay cierta tendencia a que el saldo comercial sea altamente dependiente de la actividad económica, y también de los niveles de subempleo y de explotación laboral (resultado evidenciado sobre todo en la Tabla 5). Tal conclusión refuerza la hipótesis de que las actividades económicas en el capitalismo periférico ecuatoriano, al enfrentarse a la competencia real internacional, muestran cierta tendencia a obtener superávits comerciales por medio de la obtención de ventajas absolutas de costo basadas en la sobreexplotación laboral. En cambio, la producción, el subempleo y la explotación laboral parecen estar más afectadas por dinámicas internas que por los déficits comerciales, resultado que puede entenderse debido a que en el período 2007-2016 buena parte de los recursos del segundo boom petrolero exacerbaron las importaciones en vez de generar transformaciones productivas al interior del capitalismo ecuatoriano que mejoren significativamente la calidad del empleo y de los salarios (conclusión similar a la que llegan Acosta y Cajas-Guijarro (2018) en su evaluación de la economía ecuatoriana durante la década 2007-2016).

\section{Gráfico 10. FIR transitoria y acumulada de un impulso en la "producción" (d.InPIB) y respuesta en el} resto del sistema.
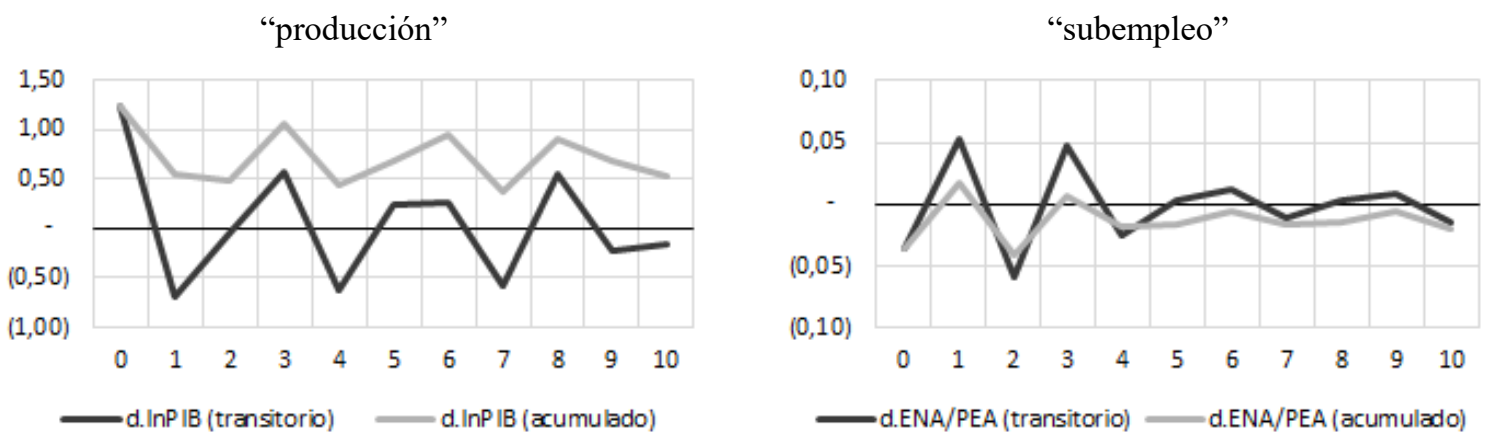

"explotación laboral"
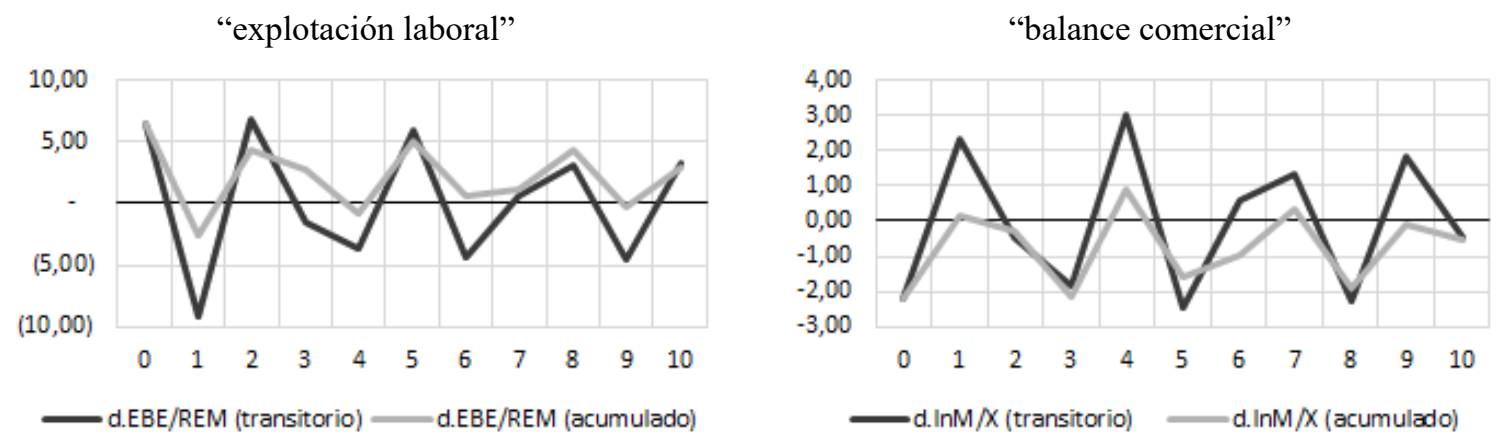

Fuente: TOU- BCE; ENEMDU-INEC; COMTRADE. Elaboración y estimación propias. 
Gráfico 11. FIR transitoria y acumulada de un impulso en el "subempleo" (d.ENA/PEA) y respuesta en el resto del sistema.

"producción"

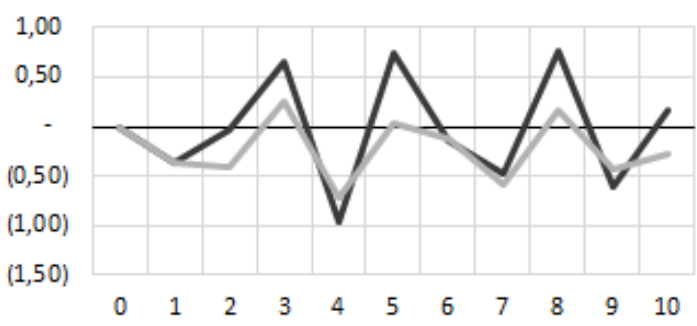

d. InP IB (transitorio) - d. InP IB (acumulado)

"explotación laboral"

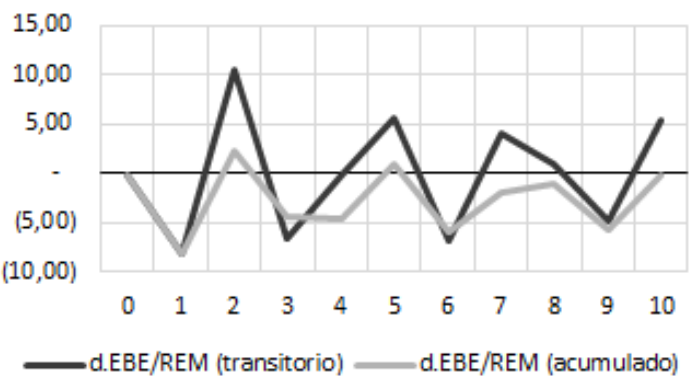

"subempleo"

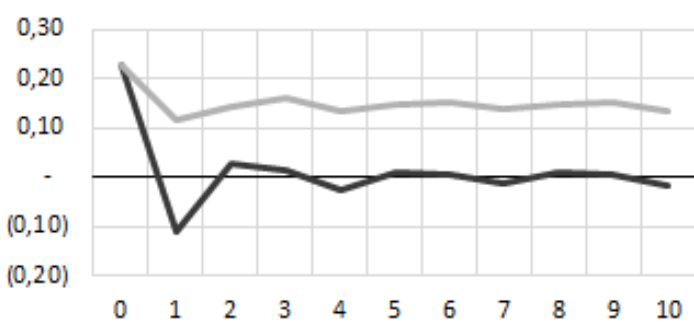

d.ENA/PEA (transitorio) d.ENA/PEA (acumulado)

"balance comercial"

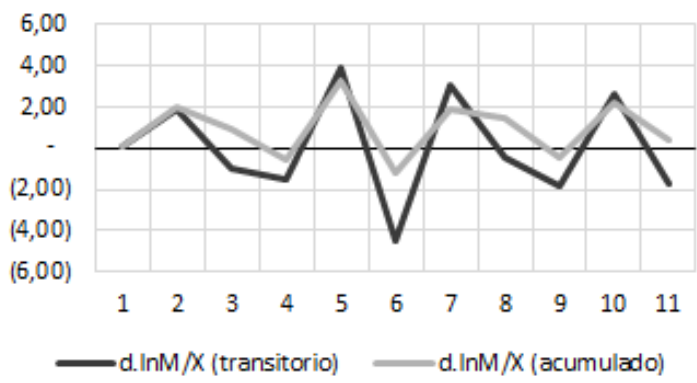

Fuente: TOU- BCE; ENEMDU-INEC; COMTRADE. Elaboración y estimación propias.

Gráfico 12. FIR transitoria y acumulada de un impulso en la "explotación laboral” (d.EBE/REM) y respuesta en el resto del sistema.

"producción"

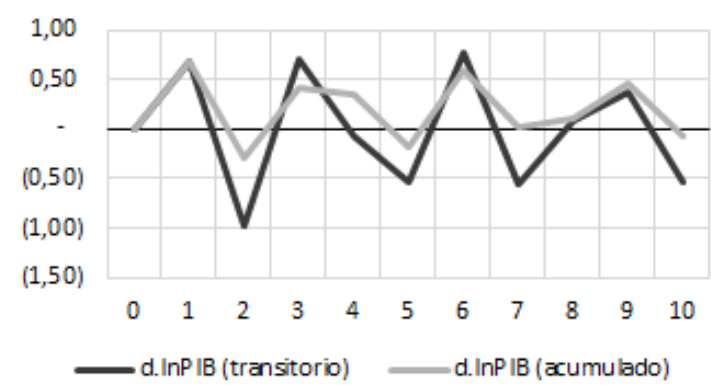

“explotación laboral”

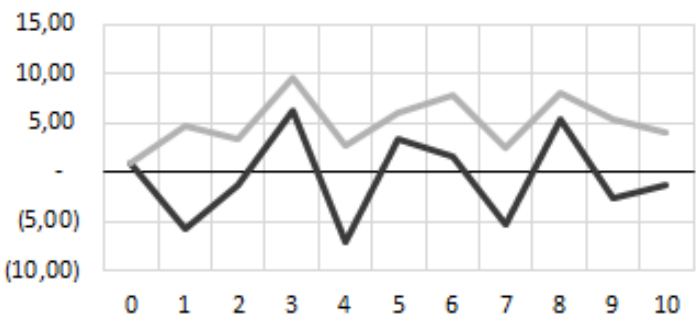

d.EBE/REM (transitorio) —d.EBE/REM (acumulado) "subempleo"

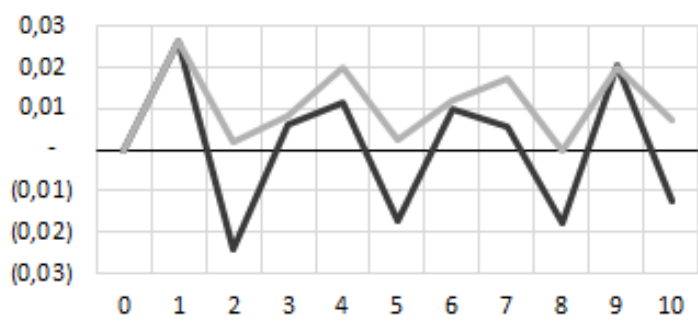

d.ENA/PEA (transitorio) -d.ENA/PEA (acumulado)

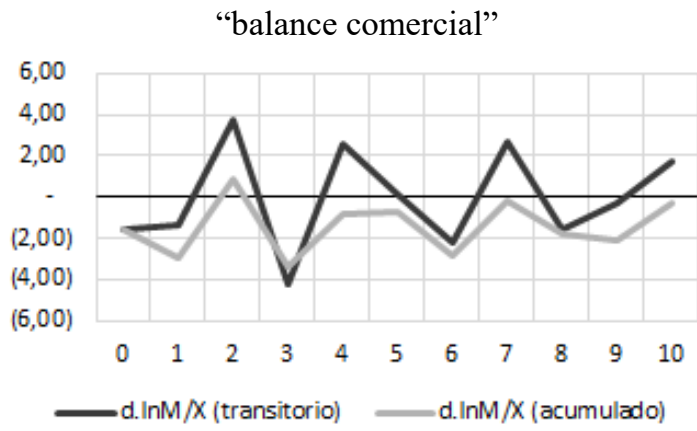

Fuente: TOU- BCE; ENEMDU-INEC; COMTRADE. Elaboración y estimación propias. 
Gráfico 13. FIR transitoria y acumulada de un impulso en el "balance comercial" (d.InM/X) y respuesta en el resto del sistema.

“producción”

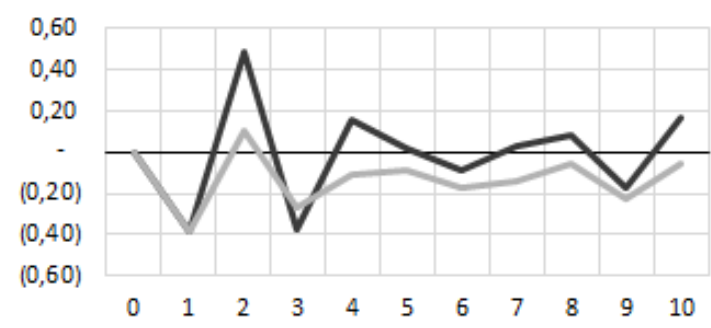

d. InP IB (transitorio)

d. InP IB (acumulado)

"explotación laboral"

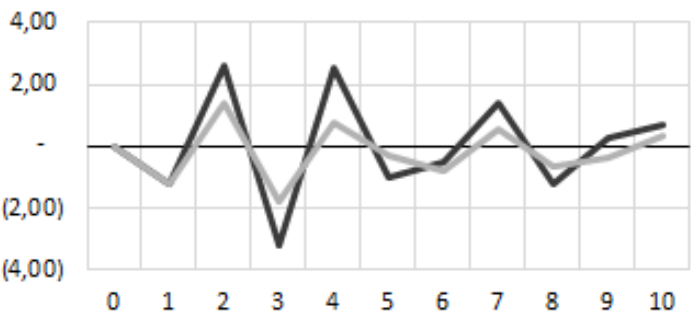

d.EBE/REM (transitorio) $\longrightarrow$ d.EBE/REM (acumulado) "subempleo"

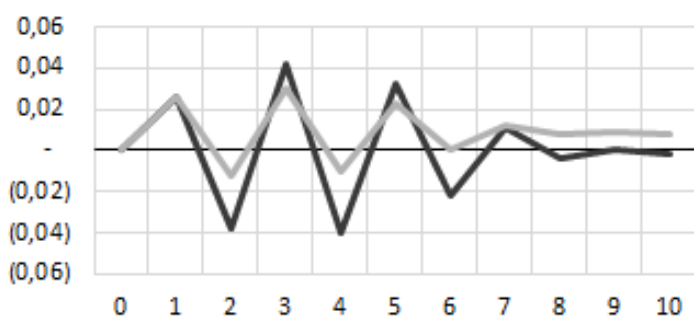

d.ENA/PEA (transitorio) —d.ENA/PEA (acumulado)

"balance comercial"

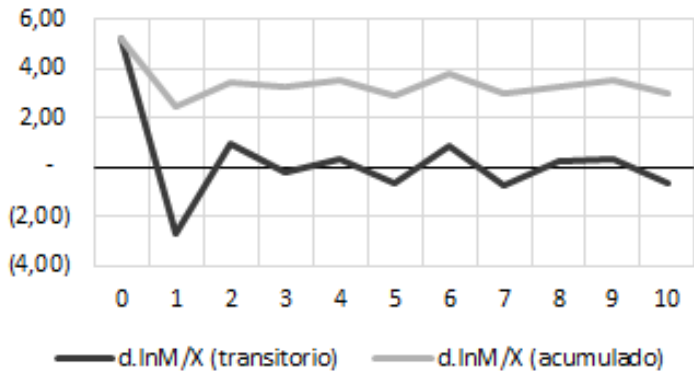

Fuente: TOU- BCE; ENEMDU-INEC; COMTRADE. Elaboración y estimación propias.

Tabla 2. FDVE de la "producción" (d.InPIB).

\begin{tabular}{|c|c|c|c|c|}
\hline Períodos & $\begin{array}{l}\text { d.InPIB } \\
\text { "producción" }\end{array}$ & $\begin{array}{l}\text { d.ENA/PEA } \\
\text { "subempleo" }\end{array}$ & $\begin{array}{c}\text { d.EBE/REM } \\
\text { "explotación laboral" }\end{array}$ & $\begin{array}{c}\mathrm{d} \cdot \ln \mathrm{M} / \mathrm{X} \\
\text { "balance comercial" }\end{array}$ \\
\hline 0 & $0 \%$ & $0 \%$ & $0 \%$ & $0 \%$ \\
\hline 1 & $100 \%$ & $0 \%$ & $0 \%$ & $0 \%$ \\
\hline 2 & $72 \%$ & $5 \%$ & $17 \%$ & $5 \%$ \\
\hline 3 & $50 \%$ & $4 \%$ & $36 \%$ & $10 \%$ \\
\hline 4 & $43 \%$ & $11 \%$ & $36 \%$ & $10 \%$ \\
\hline 5 & $40 \%$ & $23 \%$ & $29 \%$ & $8 \%$ \\
\hline 6 & $36 \%$ & $27 \%$ & $29 \%$ & $7 \%$ \\
\hline 7 & $34 \%$ & $25 \%$ & $34 \%$ & $7 \%$ \\
\hline 8 & $34 \%$ & $25 \%$ & $34 \%$ & $6 \%$ \\
\hline 9 & $34 \%$ & $29 \%$ & $31 \%$ & $6 \%$ \\
\hline 10 & $33 \%$ & $31 \%$ & $31 \%$ & $6 \%$ \\
\hline
\end{tabular}

Fuente: TOU- BCE; ENEMDU-INEC; COMTRADE. Elaboración y estimación propias. 
Tabla 3. FDVE del "subempleo" (d.ENA/PEA).

\begin{tabular}{ccccc} 
Períodos & $\begin{array}{c}\text { d.lnPIB } \\
\text { "producción" }\end{array}$ & $\begin{array}{c}\text { d.ENA/PEA } \\
\text { "subempleo" }\end{array}$ & $\begin{array}{c}\text { d.EBE/REM } \\
\text { "explotación laboral" }\end{array}$ & $\begin{array}{c}\text { d.lnM/X } \\
\text { "balance comercial" }\end{array}$ \\
\hline 0 & $0 \%$ & $0 \%$ & $0 \%$ & $0 \%$ \\
2 & $2 \%$ & $98 \%$ & $0 \%$ & $1 \%$ \\
3 & $6 \%$ & $92 \%$ & $1 \%$ & $3 \%$ \\
4 & $10 \%$ & $85 \%$ & $2 \%$ & $5 \%$ \\
5 & $12 \%$ & $81 \%$ & $2 \%$ & $7 \%$ \\
6 & $13 \%$ & $79 \%$ & $2 \%$ & $8 \%$ \\
7 & $12 \%$ & $78 \%$ & $2 \%$ & $8 \%$ \\
8 & $12 \%$ & $77 \%$ & $2 \%$ & $8 \%$ \\
10 & $13 \%$ & $77 \%$ & $2 \%$ & $8 \%$ \\
\hline
\end{tabular}

Fuente: TOU- BCE; ENEMDU-INEC; COMTRADE. Elaboración y estimación propias.

Tabla 4. FDVE de la "explotación laboral” (d.EBE/REM).

\begin{tabular}{|c|c|c|c|c|}
\hline Períodos & $\begin{array}{c}\text { d.lnPIB } \\
\text { "producción" }\end{array}$ & $\begin{array}{l}\text { d.ENA/PEA } \\
\text { "subempleo" }\end{array}$ & $\begin{array}{c}\text { d.EBE/REM } \\
\text { "explotación laboral" }\end{array}$ & $\begin{array}{c}\mathrm{d} . \ln \mathrm{M} / \mathrm{X} \\
\text { "balance comercial" }\end{array}$ \\
\hline 0 & $0 \%$ & $0 \%$ & $0 \%$ & $0 \%$ \\
\hline 1 & $29 \%$ & $0 \%$ & $71 \%$ & $0 \%$ \\
\hline 2 & $38 \%$ & $20 \%$ & $42 \%$ & $0 \%$ \\
\hline 3 & $35 \%$ & $35 \%$ & $28 \%$ & $2 \%$ \\
\hline 4 & $29 \%$ & $37 \%$ & $30 \%$ & $3 \%$ \\
\hline 5 & $28 \%$ & $33 \%$ & $35 \%$ & $4 \%$ \\
\hline 6 & $30 \%$ & $34 \%$ & $33 \%$ & $4 \%$ \\
\hline 7 & $30 \%$ & $37 \%$ & $30 \%$ & $3 \%$ \\
\hline 8 & $28 \%$ & $37 \%$ & $32 \%$ & $3 \%$ \\
\hline 9 & $28 \%$ & $35 \%$ & $33 \%$ & $3 \%$ \\
\hline 10 & $29 \%$ & $36 \%$ & $32 \%$ & $3 \%$ \\
\hline
\end{tabular}

Fuente: TOU- BCE; ENEMDU-INEC; COMTRADE. Elaboración y estimación propias. 
Tabla 5. FDVE del "balance comercial" (d.InM/X).

\begin{tabular}{ccccc} 
Períodos & $\begin{array}{c}\text { d.lnPIB } \\
\text { "producción" }\end{array}$ & $\begin{array}{c}\text { d.ENA/PEA } \\
\text { "subempleo" }\end{array}$ & $\begin{array}{c}\text { d.EBE/REM } \\
\text { "explotación laboral" }\end{array}$ & $\begin{array}{c}\text { d.lnM/X } \\
\text { "balance comercial" }\end{array}$ \\
\hline 0 & $0 \%$ & $0 \%$ & $0 \%$ & $0 \%$ \\
1 & $14 \%$ & $0 \%$ & $7 \%$ & $79 \%$ \\
2 & $20 \%$ & $7 \%$ & $8 \%$ & $66 \%$ \\
3 & $15 \%$ & $7 \%$ & $27 \%$ & $51 \%$ \\
4 & $15 \%$ & $7 \%$ & $39 \%$ & $38 \%$ \\
5 & $19 \%$ & $18 \%$ & $35 \%$ & $29 \%$ \\
6 & $19 \%$ & $28 \%$ & $29 \%$ & $24 \%$ \\
7 & $18 \%$ & $31 \%$ & $29 \%$ & $22 \%$ \\
8 & $18 \%$ & $30 \%$ & $31 \%$ & $21 \%$ \\
10 & $19 \%$ & $30 \%$ & $31 \%$ & $20 \%$ \\
\hline
\end{tabular}

Fuente: TOU- BCE; ENEMDU-INEC; COMTRADE. Elaboración y estimación propias.

\section{Conclusión.}

Este artículo ha presentado algunos argumentos teóricos y un estudio de caso como elementos a favor de la hipótesis de que la competencia real vigente en el capitalismo internacional lleva a que varias actividades económicas de los países periféricos busquen ventajas absolutas de costo a través de la sobreexplotación laboral y natural. Si bien dicha búsqueda puede contribuir a que los países periféricos obtengan superávits comerciales; sin embargo, las ventajas absolutas de costo basadas en la sobreexplotación laboral-natural parecen contribuir también a que dentro de estas economías surjan dinámicas cíclicas especialmente entre la producción, el subempleo (o empleo de fuerza de trabajo con salarios y condiciones laborales inferiores a un promedio socialmente aceptable), la explotación laboral y los balances comerciales. Todo esto afectado, a su vez, por la influencia de actividades extractivistas que tienden a distorsionar la estructura económica interna.

A nivel teórico, el artículo parte planteando que la competencia real capitalista - un proceso basado principalmente en el conflicto entre empresas que buscan lucrar y acumular sin fin - se observa tanto a nivel intra como intersectorial. En el caso de la competencia intrasectorial, es decir, bajo la producción de mercancías idénticas dentro de un mismo sector, la competencia tiende a igualar los precios de productos creados muchas veces por empresas heterogéneas en sus condiciones de producción, lo que crea diferentes estructuras de costos entre empresas y, por tanto, diferencias persistentes en sus tasas de ganancia. Todo esto lleva a que, en la competencia intrasectorial, las empresas compitan básicamente reduciendo sus costos. En cambio, en la competencia intersectorial, es decir entre sectores diferentes que producen mercancías distintas, la principal dinámica surge del movimiento de capitales enfocados a aprovechar las tasas de ganancia de los capitales reguladores (capitales con las mejores condiciones de reproducción dentro de cada sector y que usualmente presentan los costos unitarios más bajos). La interacción de ambos tipos de competencia hace que en el interior de los sectores exista heterogeneidad entre tasas de ganancia, mientras que existiría cierta igualdad en las tasas de ganancia de los capitales reguladores de diferentes sectores. 
Cuando este proceso de competencia real se lo analiza a una escala global, se nota que la competencia intrasectorial que lleva a la nivelación de precios y a la pugna por la reducción de costos se traduce en un principio de ventaja absoluta de costo: en la competencia internacional de empresas que producen mercancías idénticas, tienen ventaja aquellas con las mejores condiciones de producción y/o los salarios más bajos, todo lo que les permite alcanzar los menores costos de producción en términos absolutos. En este proceso surgen capitales reguladores globales que tienen los costos de producción más bajos, logran imponer precios de producción a escala global, y contribuyen a generar superávits comerciales a sus países de origen. En cambio, los capitales que no logran ganar ventajas absolutas de costo inducen al surgimiento de déficits comerciales. En otras palabras, la competencia real capitalista a escala internacional crea un vínculo entre ventajas absolutas de costo y los balances comerciales que mantienen los países con el resto del mundo.

Ahora, en un contexto de "desarrollo capitalista desigual" en donde el sistema mundo presenta estructuras centro-periféricas, las diferencias estructurales entre centros capitalistas y periferia provocan que las ventajas absolutas de costo tengan diferentes implicaciones para cada caso. De este modo, si se acepta la intuición estructuralista de que los centros capitalistas concentran el progreso técnico, entonces la ventaja absoluta de costo de los capitales centrales se basará principalmente en reducir costos aplicando condiciones de producción técnicamente sofisticadas. En cambio, la falta de difusión del progreso técnico junto con la posible existencia de heterogeneidad estructural provoca dos tendencias en la periferia: por un lado, la existencia de un pequeño sector moderno con ventajas absolutas de costo similares a aquellas de los capitales centrales; por otro lado, y siguiendo algunas intuiciones dependentistas, se sugiere la existencia de un importante sector tradicional que ante la falta de condiciones de producción avanzadas, basa sus ventajas absolutas de costo en la sobreexplotación de la fuerza de trabajo y de la naturaleza (sobreexplotación laboral-natural). Todo esto puede deducirse desde la competencia intrasectorial, incluso sin considerar interacciones entre centros y periferia.

Luego, al tomar en cuenta la interacción entre centros y periferia en un ambiente de competencia intra e intersectorial, se puede deducir el surgimiento de dos grandes grupos de capitales que definen el comercio internacional: capitales reguladores centrales altamente tecnificados, cuya ventaja absoluta de costo global se basa en avanzadas condiciones técnicas de producción; capitales reguladores periféricos tradicionales, que sustentan su ventaja absoluta de costo global en la sobreexplotación laboral-natural. Debido a su elevada tecnificación, se puede sugerir que los capitales centrales poseen elevadas composiciones orgánicas del capital mientras que los capitales periféricos poseen bajas composiciones orgánicas; esa diferencia hace que en la competencia intersectorial internacional emerja un intercambio desigual que va desde los países periféricos hacia los centrales, brindando a estos últimos la posibilidad de obtener importantes superávits comerciales (que también se alimentan de ganancias extraordinarias provenientes de la aplicación de trabajo potenciado). En cambio, para los países de la periferia, los superávits comerciales dependen crucialmente de las ventajas absolutas de costo basadas en la sobreexplotación laboral-natural, implicando la tendencia a que en el interior de estos países exista una elevada explotación laboral y, por ende, un elevado subempleo (a más de una intensiva explotación de recursos naturales).

Como resultado de este proceso puede surgir una dinámica cíclica al interior de los países capitalistas periféricos. Por ejemplo, si en estos países se incrementa exógenamente el producto (p.ej. a causa de una expansión autónoma de la demanda agregada), eso puede reducir el subempleo e incrementar el poder de los trabajadores para exigir mejores salarios y condiciones laborales, lo que reduce la explotación laboral. Ahora, como los capitales reguladores periféricos tradicionales basan una parte de sus ventajas absolutas de costo precisamente en la sobreexplotación laboral, entonces una menor explotación laboral reduce dichas ventajas absolutas y presiona al déficit comercial y a una potencial contracción del ingreso y la producción. Sin embargo, esa contracción puede aumentar el subempleo, debilitar a los trabajadores, aumentar la explotación laboral y recuperar la ventaja absoluta de costo basada en la sobreexplotación, con lo que se recupera el superávit comercial, aumenta el ingreso-producción y se consolida el proceso cíclico. 
Dada la hipótesis teórica de un potencial proceso cíclico en el interior de los países periféricos a causa de la vigencia de ventajas absolutas de costo basadas en la sobreexplotación laboral-natural, en un siguiente paso el artículo busca alguna evidencia empírica que refuerce esta hipótesis. Como para este fin resultan limitados los trabajos empíricos disponibles sobre el estudio de la ventaja absoluta de costo (mayormente enfocados a estudiar el comercio bilateral o el vínculo entre tipo de cambio real y costos laborales en países capitalistas medio o altamente "desarrollados"), el artículo propone el estudio de un caso concreto de país capitalista periférico con tendencias cíclicas y con actividades que potencialmente buscan ventajas absolutas de costo sustentadas en la sobreexplotación: el capitalismo periférico ecuatoriano. En efecto, dicho caso presenta ciertas tendencias históricas-cíclicas de mediano a largo plazo relevantes en variables como el crecimiento del PIB per cápita, la tasa de subempleo o de empleo no adecuado, la ratio excedente bruto de explotación / remuneraciones a los asalariados (tomada como proxy de la explotación laboral) y la ratio importaciones / exportaciones (tomada como proxy del balance comercial). Tales tendencias históricas parecen describir de forma relevante la potencial evolución cíclica del capitalismo periférico ecuatoriano durante el primer boom petrolero de los años 70, la etapa neoliberal de los 80, la crisis financiera de los 90, el segundo boom petrolero de los 2000, y el estancamiento económico especialmente desde fines de 2014 en adelante.

Aparte de estas tendencias históricas, el caso ecuatoriano también muestra a nivel de actividades económicas algunos casos en donde la vigencia de ventajas absolutas de costo por medio de sobreexplotación laboral-natural se vuelve visible: extracción de petróleo, producción de banano, café y cacao; silvicultura; cría de ganado y acuicultura. Dejando de lado la extracción de petróleo (que evidentemente es extractivista y se basa en la sobreexplotación de la naturaleza), en 2016 las cuatro actividades restantes se encuentran entre las que aportan con mayor producción a la economía, tienen a más del $40 \%$ de sus trabajadores empleados bajo condiciones no adecuadas, muestran ratios explotación/salarios mayores a la unidad (con el caso extremo de la silvicultura en donde las ganancias pueden llegar a ser hasta 40 veces mayores a los salarios), y muestran importantes superávits comerciales. De estos casos destaca la producción de banano, segunda actividad de mayor relevancia en las exportaciones ecuatorianas y que, al mismo tiempo, posee las peores condiciones de sobreexplotación laboral en el país; situación que se combina con la peculiaridad de que el Ecuador es uno de los principales exportadores de banano del mundo. Esto plantea una hipótesis, que podría trabajarse como una investigación futura, de que los sectores bananeros ecuatorianos al parecer obtienen una ventaja absoluta de costo por sobreexplotación laboral de tal magnitud que les permite volverse capitales reguladores a escala global.

Así como es posible obtener los patrones descriptivos antes mencionados, el artículo también propone la estimación de un modelo de vectores autorregresivos sobre un panel de datos compuesto por 43 actividades económicas ecuatorianas observadas durante el período 2007-2016 (que captura tanto el fin del segundo boom petrolero como el inicio de la última etapa de estancamiento registrada hasta la fecha), modelo con el que es factible evaluar empíricamente la existencia de dinámicas cíclicas entre variables proxy de la "producción" (PIB per cápita), "subempleo" (tasa de empleo no adecuado), "explotación laboral" (ratio excedente bruto de explotación / remuneraciones a los asalariados) y "balance comercial" (ratio importaciones / exportaciones). De la estimación de dicho modelo PVAR y el uso de la prueba de causalidad de Granger se ha identificado evidencia de que todas las variables consideradas poseen vínculos y retroalimentaciones estadísticamente significativas. Incluso, ha sido posible encontrar evidencia de que la "explotación laboral" causa - en el sentido de Granger - al "balance comercial" pero no al revés; tal resultado podría interpretarse como evidencia a favor de que la ventaja absoluta de costo basada en la sobreexplotación laboral influye directamente en el balance comercial de las actividades del capitalismo periférico ecuatoriano mientras que la no existencia de una relación en el otro sentido quizá significa que la sobreexplotación laboral depende más de aspectos estructurales internos del país - incluyendo la propia situación de la pugna entre clases sociales locales - antes que de aspectos externos.

Por su parte, la estimación de funciones impulso-respuesta muestra que, en términos amplios, un shock exógeno en las variables consideradas (aplicando una descomposición de Cholesky y un orden de endogeneidad de variables acorde a la propuesta teórica de este artículo) tiende a generar un 
comportamiento cíclico prácticamente en todo el sistema. Este resultado es una clara evidencia a favor de la hipótesis teórica de que la competencia real internacional tiende a generar ciclos al interior de los países capitalistas periféricos (al menos aquellos con características similares al caso ecuatoriano). A su vez, la estimación de funciones de descomposición de varianza del error de predicción sugiere que, a causa de las múltiples retroalimentaciones cíclicas de las variables consideradas, en el capitalismo ecuatoriano hay tendencia de que el balance comercial sea altamente dependiente de la actividad económica, y sobre todo de los niveles de subempleo y de explotación laboral. Tal conclusión refuerza la hipótesis de que las actividades económicas en el capitalismo periférico ecuatoriano tienden a obtener superávits comerciales por medio de la obtención de ventajas absolutas de costo basadas en la sobreexplotación laboral. Finalmente, las variables de producción, subempleo y explotación laboral parecen estar más afectadas por dinámicas internas que por los balances comerciales, resultado que podría indicar que en el período 2007-2016 buena parte de los recursos del segundo boom petrolero exacerbaron las importaciones en vez de contribuir a financiar transformaciones productivas al interior del capitalismo ecuatoriano que mejoren significativamente la calidad del empleo y de los salarios.

Este último tema igualmente se propone como hipótesis para una posible investigación futura, que tome en cuenta tanto una descripción analítica más rigurosa de la dinámica cíclica dentro de la periferia capitalista causada por la competencia real internacional, como una estimación estadística que pueda identificar tendencias estadísticamente relevantes no solo de corto plazo sino, sobre todo, de largo plazo y para un mayor número de países capitalistas periféricos (tomando en cuenta también sus distintas actividades económicas). Todo con el propósito de fomentar una discusión más amplia sobre hasta qué punto la sobreexplotación laboral y la competencia real en el capitalismo global tienden a perpetuar la condición cíclica-dependencia de la periferia; condición que posiblemente no se superará si no existen transformaciones radicales tanto al interior de los países periféricos, así como en sus vínculos con el resto del mundo.

\section{Agradecimientos}

Agradecemos a los dos evaluadores anónimos, cuyas revisiones a una versión preliminar de este artículo mejoraron notablemente su versión final, sobre todo con respecto a la propuesta teórica aquí presentada.

\section{Referencias}

Abrigo, M., \& Love, I. (2016). Estimation of panel vector autoregression in Stata. The Stata Journal, 16(3), 778-804.

Acosta, A. \& Cajas-Guijarro, J. (2016a). Ocaso y muerte de una revolución que al perecer nunca nació. Ecuador Debate, 98, 7-28.

Acosta, A. \& Cajas-Guijarro, J. (2016b). Patologías de la abundancia. Una lectura desde el extractivismo. En R. Domínguez (Ed.), Nada dura para siempre. Neo-extractivismo tras el boom de las materias primas (pp.391-425). Quito: Universidad Andina Simón Bolívar.

Acosta, A. \& Cajas-Guijarro, J. (2018). Una década desperdiciada. Las sombras del correísmo. Quito: Centro Andino de Acción Popular.

Amin, S. (1974). La acumulación a escala mundial. Ciudad de México: Siglo XXI.

Amín, S., Bettelheim, C., Emmanuel, A., \& Palloix, Ch. (1976). Imperialismo y Comercio Internacional (El intercambio desigual). Ciudad de México: Cuadernos Pasado y Presente. 
Andrews, D., \& Lu, B. (2001). Consistent model and moment selection procedures for GMM estimation with application to dynamic panel data models. Journal of Econometrics, 101(1), 123-164.

Apostolakis, G., \& Papadopoulos, A. (2019). Financial Stability, Monetary Stability and Growth: a PVAR Analysis. Open Economies Review, 30(1), 157-178.

Arellano, M., \& Bover, O. (1995). Another look at the instrumental variable estimation of errorcomponents models. Journal of Econometrics, 68(1), 29-51.

Astarita, R. (2013). Economía política de la dependencia y el subdesarrollo. Tipo de cambio y renta agraria en la Argentina. Bernal: Universidad Nacional de Quilmes.

Botwinick, H. (1993). Persistent Inequalities. Wage disparity under capitalist competition. Princeton: Princeton University Press.

Boundi, F. (2017). Determinantes de las relaciones reales de intercambio de España con Alemania (1970-2010). Un análisis econométrico de la ventaja absoluta de costo intrasectorial. Cuadernos de economía, 36(71), 489-520.

Boundi, F. (2019). Tipo de cambio real y ventaja absoluta de costo: España, 2000-2014. Investigación Económica, 78(307), 119-45.

Brana, S, Djigbenou, M., \& Prat, S. (2012). Global excess liquidity and asset prices in emerging countries: A PVAR approach. Emerging Markets Review, 13(3), 256-267.

Cajas-Guijarro, J. (2015). Clases sociales, desigualdad y subempleo en el capitalismo subdesarrollado. (Tesis de máster). Facultad Latinoamericana de Ciencias Sociales, Quito.

Cajas-Guijarro, J. (2018). La ley general de la acumulación capitalista: una reinterpretación. Revista Economía (Universidad Central del Ecuador), 70(111), 47-67.

Cajas-Guijarro, J., \& Acosta, A. (2017). Con el correísmo de regreso al W.C. Una primera lectura al ciclo capitalista de la economía ecuatoriana entre 2000-2014. En A. López Andrade, D. Terán Pazmiño, y F. Hidalgo (Eds.), Desafios del pensamiento crítico: Memorias del Décimo Congreso Ecuatoriano de Sociología y Política. Tomo I (pp.87-110). Quito: Universidad Central del Ecuador y CLACSO.

Canova, F., \& Ciccarelli, M. (2004). Forecasting and turning point predictions in a Bayesian panel VAR model. Journal of Econometrics, 120(2), 327-359.

Carballa, S, Durand, C., \& Knauss, S. (2016). Uneven development patterns in global value chains. An empirical inquiry based on a conceptualization of GVCs as a specific form of the division of labor. París: Centre d'Economie de l'Université de Paris Nord. Disponible en: https://cepn.univparis13.fr/download-attachment/8779/

Carchedi, G. (1991). Frontiers of Political Economy. Londres: Verso.

Dávila-Fernández, M., \& Sordi, S. (2019). Distributive cycles and endogenous technical change in a BoPC growth model. Economic Modelling, 77, 216-233.

Dos Santos, T. (1970). The Structure of Dependence. American Economic Review, 60(2), 231-36.

Dussel, E. (2008). Hacia un Marx desconocido. Un comentario de los Manuscritos del 61-63. Iztapalapa: Siglo XXI y Universidad Autónoma Metropolitana. 
Emmanuel, A. (1972). Unequal Exchange: A Study in the Imperialism of Trade. Nueva York: Monthly Review Press.

Gereffi, G. (2001). Las cadenas productivas como marco analítico para la globalización. Problemas del Desarrollo. Revista Latinoamericana de Economía, 32(125), 9-37.

Goodwin, R. (1967). A growth cycle. En C.H. Feinstein (Ed.), Socialism, Capitalism and Economic Growth: Essays Presented to Maurice Dobb (pp.54-58). Cambridge: Cambridge University Press.

Grinberg, N. (2016). Global Commodity Chains and the Production of Surplus-value on a Global Scale: Bringing Back the New International Division of Labour Theory. Journal of World-Systems Research, 22(1), 247-78.

Grossman, H. ([1929] 2004). La ley de la acumulación y del derrumbe del sistema capitalista: una teoría de la crisis. Ciudad de México: Siglo XXI.

Gudynas, E. (2009). Diez tesis urgentes sobre el nuevo extractivismo. En Extractivismo, política y sociedad (pp.187-225). Quito: Centro Andino de Acción Popular y CLAES.

Guerrero, D. (1995). Competitividad: teoría y política. Barcelona: Ariel.

Hadri, K. (2000). Testing for stationarity in heterogeneous panel data. The Econometrics Journal, 3(2), $148-161$.

Hamilton, J. (1994). Time series analysis. Princeton: Princeton University Press.

Hansen, P. (1982). Large sample properties of generalized method of moments estimators. Econometrica, 50(4), 1029-1054.

Harvey, D. (2003). The New Imperialism. Nueva York: Oxford University Press.

Johnson, R. (2018). Measuring global value chains. Annual Review of Economics, 10, 207-36.

Kaplinsky, R., \& Morris, M. (2000). A handbook for value chain research. Vol. 113. Otawa: Universidad de Sussex, Instituto de Estudios del Desarrollo.

Laibman, D. (1992). Value, Technical Change and Crisis: Explorations in Marxist Economic Theory. Nueva York: Routledge.

Lardic, S., \& Mignon, V. (2002). Econométrie des séries temporelles macroéconomiques et financières. París: Economica.

Lee, L., \& Yu, J. (2010). Estimation of spatial autoregressive panel data models with fixed effects. Journal of Econometrics, 154(2), 165-185.

Levin, A., Lin, C., \& James, C. (2002). Unit root tests in panel data: asymptotic and finite-sample properties. Journal of Econometrics, 108(1), 1-24.

Love, I. \& Zicchino, L. (2006). Financial development and dynamic investment behavior: Evidence from panel VAR. The Quarterly Review of Economics and Finance, 46(2), 190-210.

Marini, R.M. (1973). Dialéctica de la dependencia. Ciudad de México: ERA.

Marx, K. ([1867] 2009). El Capital. Crítica de la economía política. Libro primero. El proceso de producción del capital. Ciudad de México: Siglo XXI. 
Marx, K. ([1894] 2009). El Capital. Crítica de la economía política. Libro tercero. El proceso global de la producción capitalista. Ciudad de México: Siglo XXI.

Melguizo, C. (2015). An analysis of the Okun s law for the Spanish provinces. AQR-Working Papers, 2015, AQR15/01. Barcelona: Universidad de Barcelona. Descargado de: https://www.ub.edu/irea/working_papers/2015/201501.pdf

Myrdal, G. (1957). Teoría económica y regiones subdesarrolladas. Ciudad de México: Fondo de Cultura Económica.

Noroña, S., \& Cajas-Guijarro, J. (2014). Acumulación de capital, ejército industrial de reserva y su relación en la economía ecuatoriana. (Tesis de Ingeniería). Escuela Politécnica Nacional, Quito.

Osorio, J. (2015). El sistema-mundo de Wallerstein y su transformación. Una lectura crítica. Argumentos, 28(77), 131-153.

Pinto, A. (1969). Condiciones sociales e integración regional. El Trimestre Económico, 36(143), 395413.

Prebisch, R. (1950). The economic development of Latin America and its principal problems. Nueva York: Naciones Unidas.

Prebisch, R. (1984). Power relations and market laws. Working Paper No. 35. Indiana: Universidad de Notre Dame, Helen Kellogg Institute for International Studies. Descargado de: https://kellogg.nd.edu/sites/default/files/old_files/documents/035_0.pdf

Ricardo, D. ([1817] 1951). On the Principles of Political Economy and Taxation. Cambridge: Cambridge University Press.

Ricci, A. (2019). Unequal Exchange in the Age of Globalization. Review of Radical Political Economics, 51(2), 225-245.

Seretis, S., \& Tsaliki, P. (2016). Absolute advantage and international trade: Evidence from four Eurozone economies. Review of Radical Political Economics, 48(3), 438-451.

Shaikh, A. (1980a). Foreign trade and the law of value: part II. Science \& Society, 44(1), 27-57.

Shaikh, A. (1980b). The Laws of International Exchange. En E. Nell (Ed.), Growth, Profits and Property: Essays in the Revival of Political Economy (pp.204-235). Cambridge: Cambridge University Press.

Shaikh, A. (1990). Valor, acumulación y crisis. Bogotá: Tercer Mundo Editores.

Shaikh, A. (2008). Competition and Industrial Rates of Return. En P. Arestis \& J. Eatwell (Eds.), Issues in Economic Development and Globalisation, Festschrift in Honor of Ajit Singh (pp.167-194). Basingstoke: Palgrave Macmillan.

Shaikh, A. (2016). Capitalism: Competition, conflict, crises. Oxford: Oxford University Press.

Smith, A. ([1776] 1973). The Wealth of Nations. Londres: Penguin Books.

Sotelo, A. (2017). Sub-Imperialism Revisited. Dependency Theory in the Thought of Ruy Mauro Marini. Boston: Brill. 
Tokman, V., \& García, N. (1981). Dinámica del subempleo en América Latina. Santiago de Chile: CEPAL.

Tsaliki, P., Paraskevopoulou, C., \& Tsoulfidis, L. (2018). Unequal exchange and absolute cost advantage: evidence from the trade between Greece and Germany. Cambridge Journal of Economics, 42(4), 1043-86.

Tsay, R. (2005). Analysis of Financial Time Series. Nueva York: Wiley.

Tsoulfidis, L., \& Tsaliki, P. (2005). Marxian Theory of Competition and the Concept of Regulating Capital: Evidence from Greek Manufacturing. Review of Radical Political Economics, 37(1), 5-22.

Tsoulfidis, L., \& Tsaliki, P. (2019). Classical Political Economics and Modern Capitalism. Cham: Springer Nature.

Wallerstein, I. (2005). Análisis de sistemas-mundo. Una introducción. Ciudad de México: Siglo XXI.

\section{Anexos}

A.1 Pruebas de Estacionariedad.

\begin{tabular}{ccccc}
\hline Pruebas de estacionariedad & $\begin{array}{c}\text { InPIB } \\
\text { (p-valor) }\end{array}$ & $\begin{array}{c}\text { ENA/PEA } \\
\text { (p-valor) }\end{array}$ & $\begin{array}{c}\text { EBE/REM } \\
\text { (p-valor) }\end{array}$ & $\begin{array}{c}\text { InM/X } \\
\text { (p-valor) }\end{array}$ \\
\hline Levin-Lin-Chun & 0.000 & 0.000 & 0.000 & 0.000 \\
Hadri & 0.000 & 0.000 & 0.000 & 0.000 \\
Hadri (con diferenciación) & 1.000 & 0.995 & 0.999 & 0.999 \\
\hline
\end{tabular}

(1) Levin-Lin-Chu: Ho. Los paneles contienen una raíz unitaria; Ha. Los paneles son estacionarios

(2) Hadri: Ho. Los paneles son estacionarios; Ha. Los paneles contienen al menos una raíz unitaria.

Fuente: TOU- BCE; ENEMDU-INEC; COMTRADE. Elaboración y estimación propias.

A.2 Selección de Retardos para el modelo PVAR.

\begin{tabular}{cccccc}
\hline Lags & CD & J & MBIC & MAIC & MQIC \\
\hline 1 & 0.5988365 & 191.038 & -92.81011 & 95.03803 & 20.42315 \\
2 & 0.7207402 & 159.5056 & -29.72646 & 95.50563 & 45.76238 \\
3 & 0.9420568 & 86.11624 & -8.499811 & 54.11624 & 29.24461 \\
\hline
\end{tabular}

Fuente: TOU- BCE; ENEMDU-INEC; COMTRADE. Elaboración y estimación propias. 
A.3 Estabilidad del modelo con valores propios al interior del círculo unidad.

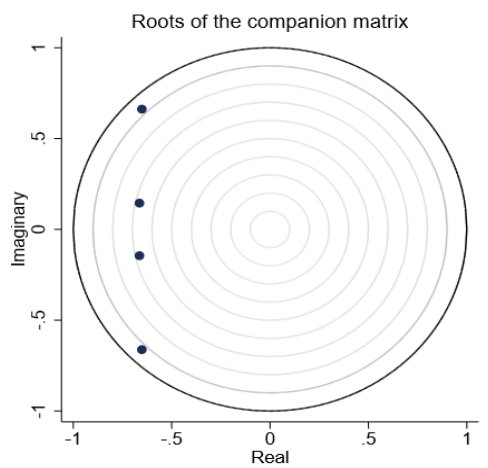

Fuente: TOU- BCE; ENEMDU-INEC. Elaboración y estimación propias. 